Human Mutation

WILEY

\title{
Clinical Variability and Novel Mutations in the NHEJ1 Gene in Patients with a Nijmegen Breakage Syndrome-like Phenotype
}

\begin{tabular}{|c|c|}
\hline Journal: & Human Mutation \\
\hline Manuscript ID: & humu-2009-0583.R1 \\
\hline Wiley - Manuscript type: & Research Article \\
\hline $\begin{array}{r}\text { Date Submitted by the } \\
\text { Author: }\end{array}$ & 27-May-2010 \\
\hline Complete List of Authors: & $\begin{array}{l}\text { Varon, Raymonda; Charité University Medical Center, Institute of } \\
\text { Human Genetics } \\
\text { Dutrannoy, Véronique; Charité University Medical Center, Institute } \\
\text { of Human Genetics } \\
\text { Demuth, Ilja; Charité University Medical Center, Institute of Human } \\
\text { Genetics } \\
\text { Konrat, Kateryna; Charité University Medical Center, Institute of } \\
\text { Human Genetics } \\
\text { Neitzel, Heidemarie; Charité University Medical Center, Institute of } \\
\text { Human Genetics } \\
\text { Radszewski, Janina; Charité University Medical Center, Institute of } \\
\text { Human Genetics } \\
\text { Rothe, Susanne; Charité University Medical Center, Institute of } \\
\text { Human Genetics } \\
\text { Sperling, Karl; Charité University Medical Center, Institute of } \\
\text { Human Genetics } \\
\text { Digweed, Martin; Charité University Medical Center, Institute of } \\
\text { Human Genetics } \\
\text { Baumann, Ulrich; Medical School Hannover, Department of Pediatric } \\
\text { Pulmonology and Neonatology } \\
\text { Schindler, Detlev; University of Würzburg, Department of Human } \\
\text { Genetics } \\
\text { Gillessen-Kaesbach, Gabriele; Universität zu Lübeck, Institute of } \\
\text { Human Genetics } \\
\text { Schellenberger, Mario; Charité University Medical Center, Institute } \\
\text { of Human Genetics } \\
\text { Keng, Wee; Jalan Residensi, Hospital Pulau Pinang } \\
\text { Nallusamy, Revathy; Jalan Residensi, Hospital Pulau Pinang } \\
\text { Reis, André; University Hospital Erlangen, Institute of Human } \\
\text { Genetics } \\
\text { Nürnberg, Gudrun } \\
\text { Nürnberg, Peter; University of Cologne, Cologne Excellence Cluster } \\
\text { on Cellular Stress Responses in Aging-Associated Diseases }\end{array}$ \\
\hline
\end{tabular}


(CECAD); University of Cologne, Cologne Center for Genomics and Institute for Genetics

Nijmegen Breakage Syndrome -like, microcephaly, NHEJ1 gene, Key Words: $\begin{aligned} & \text { Ninical variability, large genomic deletions } \\ & \text { cling }\end{aligned}$

\section{S.) ScholaroNE"}

John Wiley \& Sons, Inc. 
Humu-2009-0583

Research Article

Supporting Information for this preprint is available from the Human Mutation editorial office upon request (humu@wiley.com)

\section{Clinical Variability and Novel Mutations in the NHEJ1 Gene in Patients with a Nijmegen Breakage Syndrome-like Phenotype}

Véronique Dutrannoy ${ }^{1} *$, Ilja Demuth ${ }^{1} *$, Ulrich Baumann ${ }^{2}$, Detlev Schindler ${ }^{3}$, Kateryna

Konrat ${ }^{1}$, Heidemarie Neitzel ${ }^{1}$, Gabriele Gillessen-Kaesbach ${ }^{4}$, Janina Radszewski ${ }^{1}$, Susanne

Rothe ${ }^{1}$, Mario T Schellenberger ${ }^{1}$, Gudrun Nürnberg ${ }^{5}$, Peter Nürnberg ${ }^{5,8}$, Keng Wee Teik ${ }^{6}$, Revathy Nallusamy ${ }^{6}$, André Reis ${ }^{7}$, Karl Sperling ${ }^{1}$, Martin Digweed ${ }^{1}$, Raymonda Varon ${ }^{1 \#}$

${ }^{1}$ Institute of Human Genetics, Charitè Universitätsmedizin, Berlin, Germany;

${ }^{2}$ Department of Pediatric Pulmonology and Neonatology, Medical School Hannover, Hannover, Germany; ${ }^{3}$ Department of Human Genetics, University of Würzburg, Würzburg, Germany; ${ }^{4}$ Institute of Human Genetics, Universität zu Lübeck; Lübeck, Germany

${ }^{5}$ Cologne Center for Genomics and Institute for Genetics, University of Cologne, Cologne, Germany ; ${ }^{6}$ Hospital Pulau Pinang, Jalan Residensi, Malaysia; ${ }^{7}$ Institute of Human Genetics, University Hospital Erlangen, Friedrich-Alexander University Erlangen-Nuremberg, Erlangen, Germany, ${ }^{8}$ Cologne Excellence Cluster on Cellular Stress Responses in Aging-Associated Diseases (CECAD), University of Cologne, Cologne, Germany 
* These authors contributed equally to this work

${ }^{\#}$ Correspondence should be addressed to:

Dr. Raymonda Varon

Institute of Human Genetics

Charité, Universitätsmedizin Berlin

Augustenburger Platz 1

13353 Berlin, Germany

Tel.: 004930450566328

Fax: 004930450566904

E-mail: raymonda.varon-mateeva@charite.de

John Wiley \& Sons, Inc. 


\begin{abstract}
We have previously shown that mutations in the genes encoding DNA Ligase IV (LIGIV) and RAD50, involved in DNA repair by non-homologous-end joining (NHEJ), lead to clinical and cellular features similar to those of Nijmegen Breakage Syndrome (NBS). Very recently, a new member of the NHEJ repair pathway, NHEJ1, was discovered and mutations in patients with features resembling NBS were described. Here we report on 5 patients from 4 families of different ethnic origin with the NBS-like phenotype. Sequence analysis of the NHEJI gene in a patient of Spanish and in a patient of Turkish origin identified homozygous, previously reported mutations, c.168C>G (p.Arg57Gly) and c.532C >T (p.Arg178Ter), respectively. Two novel, paternally inherited truncating mutations, c.495dupA (p.Asp166ArgfsTer20) and c.526C>T (p.Arg176Ter) and two novel, maternal genomic deletions of 1.9 and $6.9 \mathrm{~kb}$ of the NHEJ1 gene, were found in a compound heterozygous state in two siblings of German origin and in one Malaysian patient, respectively. Our findings confirm that patients with NBS-like phenotypes may have mutations in the NHEJ1 gene including multi-exon deletions and show that considerable clinical variability could be observed even within the same family.
\end{abstract}

Key Words: Nijmegen Breakage Syndrome -like; NBS; microcephaly; NHEJI gene; clinical variability; large genomic deletions 


\section{$\underline{\text { Introduction }}$}

It has been repeatedly demonstrated that mutations in genes involved in the repair of DNA double-strand breaks (DSBs) lead to diseases combining immunodeficiency, radiosensitivity, neurodegeneration and cancer predisposition. One such condition is Nijmegen breakage syndrome (NBS), an autosomal recessive disorder, characterized by microcephaly, facial dysmorphism, growth retardation, immunodeficiency, hypersensitivity to ionizing radiation and a highly increased risk for lymphoreticular malignancy ( The international NBS Study Group (2000). The underlying gene is NBN (previously NBS1) (MIM\# 602667) and its product, nibrin, forms a complex with MRE11 (MIM\# 600814) and RAD50 (MIM\# 604040) which is involved in the repair of DNA DSBs, cell cycle control, telomere maintenance and homologous recombination (Carney et al. 1998; Varon et al. 1998).

Already with the identification of the NBN gene, genetic heterogeneity for NBS was indicated since some patients closely resembling this phenotype showed no mutations in the gene (Varon et al. 1998). Since then, a number of patients with similar clinical and cellular features but no NBN mutations have been reported in the literature, thus supporting the concept of genetic heterogeneity in NBS (Berardinelli et al. 2007; Hiel et al. 2001; Maraschio et al. 2003; Varon et al. 1998).

Recently we were able to show that some patients with features similar to the NBS phenotype have hypomorphic mutations in the DNA Ligase IV (MIM\# 601837) (O'Driscoll et al. 2001) and RAD50 genes (Bogdanova et al. 2008). While already a number of patients with mutations in LIGIV gene have been reported (Ben-Omran et al. 2005; Buck et al. 2006b; Enders et al. 2006; van Gent and van der Burg 2007), only one patient with mutations in the RAD50 gene is known so far (Bogdanova et al. 2008). It was shown that the LIGIV gene product functions in a complex 
with the XRCC4 protein and directly mediates DNA strand joining during non-homologous end joining (NHEJ). The inactivation of the LIGIV or XRCC4 (MIM\# 194363) genes in mouse cells has been shown to result in radiosensitivity and a defect in NHEJ (Barnes et al. 1998; Frank et al. 1998). However, no human phenotype has been assigned to the XRCC4 gene so far.

In an attempt to identify new factors involved in DNA repair, whose existence has been suggested before (Dai et al. 2003), two groups, Ahnesorg and colleagues and Buck and colleagues, 2006, simultaneously reported a novel gene involved in NHEJ, named XRCC4-like factor (XLF) /Cernnunos/NHEJ1 gene (MIM\# 611290). Here, we will use the official acronym of the HGNC, NHEJ1. The NHEJ1 gene product displays structural similarity to XRCC4, the binding partner of LIGIV (Chang et al. 2009), and interacts directly with the LIGIV-XRCC4 complex (Ahnesorg et al. 2006; Fernet et al. 2005; Revy et al. 2006; Yano et al. 2008). It was shown that mutations in the NHEJ1 gene lead to profound immunodeficiency due to T- and Blymphocytopenia, microcephaly, developmental delay and cellular sensitivity to ionizing radiation, features common with the ones observed in patients with NBS and LIGIV syndromes. However, in contrast to NBS, deficiency of the NHEJI gene does not lead to impaired cell cycle checkpoints and none of the known patients so far has developed malignancy (Buck et al. 2006a; Carney et al. 1998; Dai et al. 2003). Until now, only 6 patients with (recessive) mutations in the NHEJ1 gene have been described (Ahnesorg et al. 2006; Buck et al. 2006a). Here we report on further 5 patients from 4 families with $N H E J 1$ deficiency due, in 3 of them, to novel mutations in this gene.

\section{Materials and Methods}

\section{Patients}


Five patients from 4 families of Spanish, Turkish, German and Malaysian origin are described in this paper. DNA was extracted from EDTA-blood according to a standard procedure from all five patients, their parents and healthy siblings after written informed consent. The Spanish and the Turkish families were consanguineous. All patients were referred to our laboratory for mutation analysis of the NBN gene to confirm a prior clinical diagnosis of NBS. Analyses of the $N B N$, LIGIV and RAD50 genes, showed no mutation. The main clinical and mutational data of all five patients are summarized in Table 1. A detailed clinical description of the patients is available as Supporting Information.

\section{Homozygosity Mapping}

After negative molecular analysis for the NBN and LIGIV genes in the consanguineous Spanish family, we carried out a genome-wide homozygosity mapping with the 10K Affymetrix SNP Chip. Multi-Point analysis showed significant linkage in the family with a LOD score of 2.05 on chromosome $2 q 35$. The flanking SNP markers defined a region of about $17 \mathrm{cM}$.

\section{Cell Cycle Analysis}

Cell-cycle analysis was performed in PHA-stimulated lymphocytes in P2 and P3 and in cultured fibroblasts in P1 with and without irradiation using 5-bromo-2'-deoxyuridine (BrdU)-Hoechst 33258 flow cytometry. Irradiated and non-irradiated patients' cells and control cultures were harvested after $72 \mathrm{~h}$. The cells were stained with $1.2 \mu \mathrm{g} / \mathrm{ml}$ Hoechst for $15 \mathrm{~min}$ and subsequently with $1.5 \mu \mathrm{g} / \mathrm{ml}$ propidium iodide (PI) for another $15 \mathrm{~min}$ at $4{ }^{\circ} \mathrm{C}$ in the dark. Bivariate flow histograms were recorded on an analytical, triple laser-equipped 
flow cytometer (LSRII, Becton Dickinson) using UV excitation of the Hoechst dye and 488-nm excitation of PI. The resulting cell cycle distributions reflecting cellular DNA content and cell cycle progression were quantified using the MPLUS AV software package (Phoenix Flow Systems). A correction for cells having divided once, twice, or more times was introduced to truly reflect the fate of the cells initially placed in culture independent of their proliferative capacity. The results were compared with cells derived from a normal control subject and patients with AT and LIGIV deficiency.

\section{Chromosome Analysis}

Chromosome analysis was performed in cultured skin fibroblasts for P5 using standard techniques. Patient 4 was analyzed elsewhere. Irradiation of cells was carried out using the X-ray apparatus Muller MG 150 (UA = $100 \mathrm{kV}, \mathrm{I}=10 \mathrm{~mA}$, filter $0.3 \mathrm{~mm} \mathrm{Ni}$, dose rate: $2.1 \mathrm{~Gy} / \mathrm{min}$ ) with doses $0.5,1.0$, and 2.0 Gy. Radiosensitivity was determined by analysing the number of breaks per cell in 75 metaphases per irradiation dose. The results were compared with fibroblasts derived from a normal control subject and a patient with NBS.

\section{Molecular Analysis}

After no mutations were found in NBN, LIGIV and RAD50 genes, all patients were analyzed for mutations in the recently identified NHEJlgene by means of PCR and direct sequencing.. The sequences were compared to the NCBI reference sequence MN_024782.2 for the NHEJ1 gene. The nucleotide numbering of the mutations reflects cDNA numbering with +1 corresponding to the A of the ATG translation initiation codon in the reference sequence, according to (www.hgvs./org/mutnomen) To identify the second NHEJ1 mutation in the German family, 
introns 1, 2 and 3 of the gene were amplified and sequenced with overlapping primers covering the whole sequence (primer sequences are available on request). All samples were run on the ABI PRISM 3730 analyzer. Haplotypes, based on the polymorphisms found for the German and Malaysian family were constructed.

In addition, we also sequenced the $X R C C 4$ gene as a potential modifying gene to explain the clinical variability observed in the German family.

\section{RT-PCR}

After written informed consent, EBV-immortalized lymphoblastoid cell lines (LCL) of all members of the Spanish, German and Malaysian families were set up according to standard procedures. Several attempts to establish LCLs from patients P1, P2, P4 and P5 failed. For P1 and P5, fibroblast cell lines could be established. RNA was extracted from cultured LCLs (Trizol) from all members of the German family with the exception of $\mathrm{P} 2$, and from the parents of the Malaysian patient. A small amount of RNA from P2 was extracted by using the PAX gene blood RNA-System following the manufacturer's instruction.

For first-strand cDNA synthesis, $2 \mu \mathrm{g}$ RNA of each sample, M-MLV reverse transcriptase and random hexamer primers were used. The subsequent RT-PCR reaction used $2 \mu 1$ of the cDNA product and specific $N H E J 1$ gene primers, covering the whole mRNA in overlapping fragments: exons 1-4 (RT_Ex1F CGCGGCCGCTGACGGTCTCCCAACATTTGAT and RT_Ex4R GTCTTTCATATGAAGTAACGT and exons 4-8 (RT_Ex4F CTGATGGGCATGAGTCTGGCA and RT_Ex8R GCAGCTGAGGCCACAACAGAT). The 
resulting PCR-product(s) were cloned with the TOPO Cloning Kit, sequenced with M13 universal primers and run on the ABI PRISM 3730 analyzer.

\section{Quantitative Genomic PCR}

To detect the genomic deletions in the German and Malaysian patients suggested by the SNP haplotypes, we performed quantitative PCR at the DNA level. Walking primers were designed covering the regions suspected to be deleted (primer sequences are available as Supporting Information). DNA copy number determination by quantitative PCR was performed by using “Power SYBR Green PCR Master Mix" (ABI) and the ABI 7500 Real-Time PCR System. All samples were analyzed in duplicate and the Ct-values were compared with these of the control samples run in parallel. Relative gene copy numbers were calculated by using the $\Delta \Delta \mathrm{Ct}$ method. The exact positions of the deletion break points in the German and Malaysian patients were confirmed by amplification and sequencing of the junction fragments.

\section{SNP-Analysis}

In order to check whether the transcripts carrying the truncating mutations found in the German, Malaysian and Turkish patients are eliminated selectively by the mRNA surveillance mechanism nonsense-mediated mRNA decay (NMD), we carried out a SNP-analysis for the paternally inherited mutations in the corresponding families, comparing the mutant and normal alleles at the DNA and RNA level. We used the ABI SNaPshot Multiplex kit and the samples were run on the ABI PRISM 3730 analyzer. 


\section{Western Blot Analysis}

Proteins were isolated from LCLs of P3, his healthy brother and parents according to standard procedures. Blots were probed with a rabbit polyclonal antibody (Novus Biologicals) directed against the C-terminal portion of the NHEJ1 gene product (residues 250-299). Antibodies to MRE11 (Novus Biologicals) and actin (Amersham) were used as controls.

\section{Repeat Masker Program}

Searching for a potential explanation for the occurrence of the genomic deletions found in P2, P3 and P4, we analyzed the breakpoints flanking sequences for repetitive elements by using Repeat masker program (http://www.repeatmasker.org).

\section{$\underline{\text { Results }}$}

\section{Homozygosity Mapping}

The striking clinical and cellular similarities between the Spanish patient and NBS patients together with the fact that no mutations were detected in the NBN, LIGIV or RAD50 genes, prompted us to search for an alternative gene locus in this family. Since the parents were consanguineous, we carried out a homozygosity mapping with the 10K Affymetrix SNP Chip and found linkage to chromosome 2q35 with a Lod score of 2.05. Fine mapping with microsatellites narrowed further the initial critical region of $17 \mathrm{cM}$ to the $12 \mathrm{cM}$ between markers D2S164 and D2S439. A total of 6 candidate genes in this region, all functionally relevant for the NBS phenotype, were sequenced and excluded as disease causing genes in this family. 


\section{Molecular Analysis}

Ahnesorg et al. and Buck et al. (Ahnesorg et al. 2006; Buck et al. 2006a) reported the identification of a novel gene, $N H E J 1$, involved in DNA repair through the non-homologous end joining pathway (NHEJ). This newly described gene, designated as FLJ12010 in the database (http://www.ncbi.nlm.nih.gov/), was located in our region of interest on chromosome 2q35. Sequencing of the NHEJ1 gene in the Spanish patient (P1) revealed the homozygous missense mutation, c. 168C >G (p.Arg57Gly) in exon 2, also reported by Buck et al. (2006a). Segregation analysis confirmed the presence of the mutation and the variant in the family (data not shown). After the NHEJ1 gene mutation was detected in the Spanish family, we screened a total of 120 patients with an NBS-like phenotype, collected over the last 10 years for mutations in NHEJ1. The analysis revealed two novel paternally inherited heterozygous mutations in two patients of German (P2) and Malaysian (P4) origin. The mutation in P2 was a one base duplication of adenine in exon 4 of the NHEJI gene at position 495 leading to a frameshift and stop codon 20 amino acids downstream; c.495dupA (p.Asp166ArgfsTer20) (Fig. 1A), and in P4 - a heterozygous nonsense mutation, also in exon 4, leading to a truncated protein, c.526C $>\mathrm{T}$ (p.Arg176Ter) (Fig. 2A). In one further patient of Turkish origin with typical NBS phenotype recently referred to us, a known homozygous nonsense mutation in exon 5 was detected, c. 532C >T (p.Arg178Ter), (data not shown).

Further sequencing of the NHEJ1 gene failed to detect the second maternal mutation in P2 and P4. However, the presence of deleterious mutations on one allele in both patients and their NBS appearance, suggested the existence of a second mutation, not detectable through conventional mutation screening at the DNA level. 
Segregation analysis in the German family showed that the healthy brother and the newly born third child were both heterozygous for the paternal NHEJ1 c.495dupA (p.Asp166ArgfsTer20) mutation.

In an attempt to identify the second mutation in P2, we continued analysis at the RNA level. RT-PCR was carried out with 2 sets of primers covering the whole coding sequence of the NHEJ1 gene. Two transcripts were detected in $\mathrm{P} 2$, his mother and the new born child (P3) by amplifying the cDNA with primers located in exons 1 and 4 . In addition to the expected product of $576 \mathrm{bp}$, a smaller product of $186 \mathrm{bp}$ was seen in the agarose gel. The smaller PCR product was present neither in the father nor the healthy child, nor in control samples run in parallel (Fig. 1B). To define exactly the nature of this aberrant transcript, the RT-PCR products were cloned and analysed by sequencing. The sequence analysis of the products spanning exons 1-4 identified an aberrantly spliced transcript lacking exons 2 and 3 in P2, the newborn child (P3) and their mother (Fig. 1C shown only P2). This transcript was not seen in more than 40 control samples additionally analyzed (data not shown). This finding confirmed that this aberrant transcript reflects the second, maternally inherited mutation in this family.

The molecular basis for the occurrence of the aberrant transcript in the German family was unknown. We hypothesised that an intronic mutation, destroying a putative cryptic splice site might be responsible for the aberrant splicing and to prove this, we sequenced in their entirety introns 1, 2 and 3 of the gene, which encompass approx. $10 \mathrm{~kb}$. We found only polymorphisms which could not explain the presence of the aberrant transcript. However, we noticed that the mother, who showed homozygosity for 13 of 14 variants, was heterozygous for a SNP in intron 3 (rs55728979), close to exon 4. P2 and the newborn child P3 were homozygous for this particular polymorphism while the healthy child of the family was heterozygous (Fig. 1D). This finding 
suggested that the second mutation in the German family might be a large genomic deletion rather than a splicing mutation. The deletion was predicted to encompass introns 1 to 3 without affecting the accurate splicing of exon 1 to exon 4.

To check this prediction we designed genomic primers covering intron 1 , exon 2 , intron 2 , exon 3, intron 3, exon 6 and exon 7 and carried out quantitative PCR. We found a deletion of $1.9 \mathrm{~kb}$ from intron 1 to intron 3 . The break point at the 5 ' end was located 805 bp before exon 2 , and the 3'-end break point was located 188 bp downstream of exon 3 (Fig. 1E). The deletion was confirmed by competitive- PCR with 3 primers, 2 forward primers located in intron 1 and exon 3, and a common reverse primer in intron 3. The 494 bp band found in both patients and their mother covers the breakpoints of the deletion and derives from the mutant allele. The $663 \mathrm{bp}$ fragment is generated from the wild type allele (Fig. 1F, G). Haplotype analysis (data not shown) in the Malaysian family based on the intragenic SNPs detected during the mutation screening strongly suggested that the second mutation here could also be a genomic deletion. Indeed, quantitative PCR with genomic primers revealed an even larger, maternally inherited, genomic deletion leading to a loss of approximately $6.9 \mathrm{~kb}$ of genomic sequence (Fig. 2B). We were able to amplify a fragment of $649 \mathrm{bp}$ with primers flanking the deletion. The amplified and sequenced junction fragment confirmed the deletion breakpoints, (Fig. 2C, D). The deletion encompasses 1295bp upstream of exon 1, including the region of the minimal promoter of the $N H E J 1$ gene, 3330bp spanning the sequence between exon 1 to exon 3 and 2329 bp of intron 3.

We sequenced in addition the XRCC4 gene in the German family searching for modifying factors which could possibly explain the phenotypic differences in this family. We detected two 
heterozygous polymorphisms - c.921T>G (p.Ser307Ser) (rs1056503) and c.894-7G>A (rs1805377) and in P2 but not in P3.

\section{SNP-Analysis}

Transcripts carrying premature stop codons are frequently eliminated by the NMD mechanism. We found truncating mutations in all patients described here with the exception of P1. To quantify the alleles carrying the truncating mutations we performed comparative analysis at the DNA and RNA level by the SnapShot method by using the samples of the corresponding heterozygous parents in order to eliminate the influence of the second mutant allele in the patients. Fig. 3(A and B) shows the results of the SnapShot analysis of the paternal mutation in the German family (Fig. 3A) and the mutation in the Turkish family (Fig. 3B) (data for P4 not shown). While both alleles are almost equally represented at the DNA level, at cDNA level the expression of the allele carrying the truncating mutation is reduced to $\sim 30 \%$. Essentially the same observations were made by comparing the profiles from genomic sequencing with cDNA sequencing (data not shown). These results are consistent with the expected degradation of the mutated mRNA.

\section{Western Blot Analysis \\ Western blot analysis was carried out for the German family and showed clearly less NHEJ1 protein in P3 as compared to the parents and the healthy brother. Unfortunately, we were not able to include $\mathrm{P} 2$ in the protein analysis (Fig. 1H).}

\section{Cell Cycle and Chromosome Analysis}


The example of patient P3 shows how radiosensitivity can block progression of NEHJ1-deficient lymphocytes through the cell cycle. In 72-h-cultures, non-irradiated cells are distributed within four consecutive cycles (Fig. 4A). Following irradiation with 1.5 Gy prior to PHA-stimulation of the same cells, a prominent track of debris is detected, an elevated cell fraction remains in a resting state $(\mathrm{G} 0 / \mathrm{G} 1)$ and the majority of cycling cells are arrested in the $\mathrm{G} 2$ phase of the first cycle with only few cells reaching the G1 phase of the second cycle (G1') such that a dramatically different cell cycle distribution emerges (Fig. 4B, arrows). The extent of increase of G2 phase accumulation relative to growth fraction is shown in Fig. 4C. Patients P1, P2 and P3 reveal very high radiosensitivity with great differences of non-irradiated cells and cells irradiated with $1.5 \mathrm{~Gy}$, resulting in $\mathrm{G} 2$ ratios at the upper limit of the ataxia telangiectasia range. Indeed, initial recognition of cellular radiosensitivity in patients P1, P2 and P3 was based on flow cytometric cell cycle studies. Fig. 5D demonstrates the steep increment of G2 phase accumulation with irradiation of NHEJ1-deficient lymphocytes. Radiosensitivity of cells from patients P1, P2 and P3 as assessed by flow assay was even greater than that of cells from A-T patients. G2 phase blockage of lymphocytes from a patient with DNA ligase IV deficiency fell in the mean range of A-T cells (Fig. 4C, D).

Radiosensitivity was assessed by chromosomal breakage test in fibroblasts of P5 in response to 0.5 and 1.0 Gy radiation (Fig. 5). The chromosomal damage following radiation was compared to that of a normal control cell line and a cell line of an NBS patient. The cells of P5 showed a high spontaneous breakage rate (0.38; normal range: 0.00 to 0.06$)$ and extremely high levels of damage after IR which were higher than those of an NBS patient. The percentage of multiaberrant cells ( $>8$ breaks per cell) was increased to $28 \%$ at $0.5 \mathrm{~Gy}$ and $80 \%$ at $1.0 \mathrm{~Gy}$. 


\section{Analysis of the Sequences Surrounding the Genomic Deletions}

In order to obtain clues about the mechanism underlying the genomic deletions found in our patients, we examined precisely the sequences surrounding the break points by using Repeat Masker Program (http://www.repeatmasker.org).

The analysis failed to reveal repetitive sequences directly in the deletion breakpoints in either patient. However, examination of the sequences across the deletion breakpoints of patient 2 revealed a $4 \mathrm{bp}$ homologous sequence $(\underline{\mathrm{GAGT}})$ at the 5' and 3' breakpoints. The $4 \mathrm{bp}$ short repeat was present once more, $3 \mathrm{bp}$ downstream of the 3 ' breakpoint. Interestingly, these $3 \mathrm{bp}$ were inverted to the last $3 \mathrm{bp}$ of the GAGT repeat (Supp. Figure S2A). In addition, the sequence downstream of the 3' deletion breakpoint in P2 showed low homology to 4 LINEs and a SINE repetitive element, the nearest of them located $22 \mathrm{bp}$ from the deletion junction. No such sequences were detected in the vicinity of the 5 ' deletion breakpoint.

Similar to $\mathrm{P} 2$, a short sequence homology of $2 \mathrm{bp}$ (AC), potentially responsible for the deletion, was present at the 5' and 3' deletion breakpoints in the Malaysian patient (Supp. Figure S2B). Low homology to an MER1 repetitive element was found at the 5' breakpoint; however, it is located $623 \mathrm{bp}$ proximal to the deletion.

\section{$\underline{\text { Discussion }}$}

Two major pathways are mainly responsible for the repair of DSBs in eukaryotes, homologous recombination (HR) and non-homologous-end joining (NHEJ) (Cahill et al. 2006; Takata et al. 1998). A number of genes, involved in DSB repair, both by HR and NHEJ, have already been assigned to different human chromosomal instability disorders such as AT, NBS, LIGIV- 
Syndrome, ATLD, RS-SCID etc. (Buck et al. 2006b; Neveling et al. 2007; O'Driscoll et al. 2001; Savitsky et al. 1995; Stewart et al. 1999; Varon et al. 1998).

The most recently identified member of the NHEJ pathway, NHEJ1, located on chromosome 2q35, was shown to be mutated in patients with clinical features resembling NBS (Ahnesorg et al. 2006; Buck et al. 2006a).

Sequencing of the NHEJI gene allowed us to identify the causative mutations in 5 patients from 4 families, referred to us for molecular diagnosis of NBS. Apart from the two previously reported mutations found in P1 and P5 (Buck et al. 2006a), we identified four novel mutations in the NHEJ1 gene in 3 further patients. These patients, two of them siblings of German origin and one child of Malaysian origin were compound heterozygous for a paternally inherited truncating mutation, c.495upA (p.Asp166ArgfsTer20) and c.526C>T (p.Arg176Ter), and a large maternal deletion of $1.9 \mathrm{~kb}$ and $6,9 \mathrm{~kb}$ genomic sequence, respectively. The consequence of the deletion in the German family was an aberrant transcript lacking sequences of exons 2 and 3.

It has been shown that large genomic deletions, although not as common as the other mutations, could significantly contribute to the number of pathogenic mutations (Cavalieri et al. 2008;

Cavalieri et al. 2006; Engert et al. 2008; Masson et al. 2006; Niel et al. 2006; Savino et al. 2003; Taulan et al. 2007). Large genomic deletions usually occur as a result of errors during homologous or non-homologous recombination and involve DNA sequences with short homology flanking the breakpoints, such as A-T rich sequences, palindromes or topoisomerase I and II consensus sites (Bacolla et al. 2004; Chen et al. 2005; Dai et al. 2003; Saran et al. 2006; Yeoh et al. 2006); (Cavalieri et al. 2006; Guenther et al. 2004).

To better understand the possible mechanisms for the occurrence of the two deletions found in our patients, we analyzed the DNA sequences flanking the deletion breakpoints. The analysis 
showed that neither deletion has occurred directly between repetitive sequences. However, the deletion breakpoints in both patients did reveal short sequence homologies adjacent to the junction - $\underline{\text { GAGT }}$ in P2 (3) and $\underline{\mathrm{AC}}$ in P4. Such short repetitive elements are often located at the 5' and 3' breakpoints flanking a deletion and might be generated by slipped mispairing during DNA replication (Chen et al. 2005; Efstratiadis et al. 1980; Magnani et al. 1996). We suggest that such a scenario could be the underlying mechanism leading to the occurrence of the deletions described in this study.

The genomic deletions described here are the first reported for patients with autosomal recessive NHEJ1 deficiency. Recently, a balanced chromosomal translocation t(2;7)(q35;p22), leading to a haploinsufficient disruption of the NHEJI gene was found in a patient with polymicrogyria, a common malformation of the human cerebral cortex (Cantagrel et al. 2007). The authors showed that NHEJI is the only gene affected by the translocation and that a truncated transcript, containing only exons 1-5 is produced. In addition, they showed that the NHEJ1 gene is preferentially expressed in the telencephalic ventricular and subventricular zones of human embryos and suggest a role of the gene in the development of the human cerebral cortex. However, we feel that the polymicrogiria in the patient described cannot be explained merely by haploinsufficiancy, but rather, by a contiguous condition, since the heterozygous parents of patients with NHEJ1 deficiency are healthy.

At the time we carried out the molecular analysis in P2, the third child, P3, of the German family was born. Subsequent analysis of the newborn revealed that the boy was also a compound heterozygote for the mutations found in his affected brother and thus would also be expected to be affected. These findings were quite surprising because the newborn child was clinically healthy, apart from a mild lymphopenia, detected during episodes of several pulmonary 
infections shortly after birth. In contrast to his older brother, the child had no apparent microcephaly and no profound immunodeficiency. At the same time, at the cellular level P3 showed a similarly high radiosensitivity as his brother, typical for patients with NHEJ1 gene mutations (Ahnesorg et al. 2006; Buck et al. 2006a). These findings indicated that there may be great intrafamilial clinical variability despite relatively uniform cellular features. In addition, difficulties are often experienced in establishing of LCL's from patients with chromosomal instability disorders and while we were unable to establish an LCL of P2, it was no problem to establish the cell line for the newborn child, P3. These striking phenotypic differences between $\mathrm{P} 2$ and $\mathrm{P} 3$ prompted us to search for an explanation.

The aberrant transcript, lacking exons 2 and 3, a consequence of the deletion between intron 1 and intron 4 found in P2 and P3, is predicted to remain in-frame. The regular start codon for NHEJ1 is in exon 2, however, an alternative initiation of translation could theoretically occur from an ATG codon at position 150, 10 amino acids downstream of the beginning of exon 4 . However, in a conventional Western blot analysis we observed a decreased amount of full length NHEJ1 protein in $\mathrm{P} 3$, but no truncated protein corresponding to the putative alternative translation. It has already been mentioned that the NHEJ1 protein is involved in NHEJ required for DNA DSB repair and V(D)J recombination (Ahnesorg et al. 2006; Buck et al. 2006a; Tsai et al. 2007) by interacting with the XRCC4-LigIV complex (Andres et al. 2007; Hentges et al. 2006; Lu et al. 2007). It was shown, that while the N-terminal fragment of the NHEJ1 protein, residues $1-170$, is highly conserved and responsible for the interaction with XRCC4, the Cterminal 75 amino acid residues are required for stimulation of mismatched DNA ligation and DNA binding (Andres et al. 2007). If the aberrant transcript found in the German family did produce a truncated protein in very low amounts, it might have some residual activity 
considering its intact C-terminal portion and preservation of 20 of the amino acids involved in the interaction with XRCC4-LIGIV. The presence of such a transcript, with partially retained function in a higher amount in P3 than in P2 could be an explanation for the phenotypic differences observed in the family. Unfortunately, such direct comparison between P2 and P3 was not possible because of lack of RNA of P2. Another explanation for the milder clinical course of P3 could be modifying genetic factors which could, for example, influence the binding of the NHEJ1 protein to the LIGIV-XRCC4 complex. It has recently been shown that patients with the same homozygous LIGIV mutation could have different disease courses due to two polymorphisms, A3V and T9I. The additional presence of these two polymorphisms negatively modulates the activity of the LIGIV protein and the affected individual has developmental delay including microcephaly, while the patient carrying only the mutation is developmentally normal (Girard et al. 2004). Since these modifying polymorphisms were not found in the German family during the sequencing of the LIGIV gene we sequenced additionally the other binding partner of the NHEJI gene, XRCC4. Different variations in this gene have repeatedly been associated with a number of cancer predispositions (Chang et al. 2009; Hsu et al. 2009; Liu et al. 2008; Yen et al. 2008). Surprisingly, we found two heterozygous variants in the XRCC4 gene, namely c.921T>G (p.Ser307Ser) (rs1056503) and c.894-7G >A (rs1805377) in P2 but not in P3. The SNP rs1056503, together with other SNPs has recently been associated with a risk of glioma (Liu et al. 2008). Of special interest is the second polymorphism in intron 7, c.894-7G>A (rs1805377), which leads to alternative in frame splicing and is a common allele. Taking into consideration that the excluded codons from the transcripts produced by the G allele occur within the evolutionary conserved XRCC4 binding domain and the important role which this gene plays in NHEJ, (Nalla and Rogan 2005) speculated that this allele could negatively influence the repair 
of double strand breaks. The presence of the two XRCC4 polymorphisms in $\mathrm{P} 2$, and especially the (rs1805377) could modify the function of the NHEJ1 protein and thus influence the clinical course. One possible explanation for the effect of the polymorphisms is that they might disturb the efficient binding of the XRCC4 to the partially preserved $20 \mathrm{~N}$-terminal domain of the NHEJ1 protein. In contrast, the binding capacity in P3 would not be disturbed, possibly explaining the milder clinical course and lack of microcephaly.

There are a number of examples in the literature where clinical variability among carriers of the same mutation, even within one family, has been documented. We described recently also clinical variability in two siblings with NBS, carrying the same mutation (Varon et al. 2006). Similar strong phenotypic intrafamilial variability has been documented in patients with Cystic Fibrosis. Different, genetically determined factors, referred to as gene modifiers, have been made responsible for the phenotypic variability in some conditions (Genin et al. 2008).

As already mentioned, with the exception of P3, all patients described in this study, as well as all 6 previously reported patients with $N H E J 1$ gene deficiency, presented with microcephaly at birth, an accompanying characteristic in a number of genetic disorders with mutations in genes involved in the DNA damage response, assumed to be a consequence of reduced proliferation and/or an increased rate of apoptosis (O'Driscoll and Jeggo 2008). Microcephaly is a hallmark of NBS. However, Chrzanowska et al. have described an atypical NBS patient without microcephaly (Chrzanowska et al. 2001). Actually, cranial MRI analysis showed an abnormal parieto-occipital cerebrospinal fluid collection in the brain of this patient, as being responsible for the apparently normal head circumference. A similar situation could be assumed for P3 in our study. Follow-up of the patient and MRI analysis of the brain will probably shed more light on the pathogenesis of the disease in this patient. Interestingly, absence of microcephaly and 
developmental abnormality but fertility defects and chromosomal instability has recently been reported for two adult siblings, compound heterozygote for two truncating $N B N$ mutations. The authors hypothesized that the very mild phenotype of these patients must be due either to a partially preserved NBN functions or to certain modifier factors (Warcoin et al. 2009).

Heterogeneity in terms of developmental delay, including microcephaly has also been observed in patients with ATLD (Fernet et al. 2005).

As in the German family, comparison of the wild type allele and the allele carrying the truncating mutations at the DNA and RNA level in P4 and P5 indicated that the mutant allele is partially, degraded by NMD. On the other hand, we showed by analyzing maternal RNA that the maternal transcript in P4 (data not shown) is not expressed due to the deletion of the promoter region, thus predicting a severe clinical course in the Malaysian patient. Actually, the child is in a stable condition, due to regular immunotransfusion and antibiotic prophylaxis, however, the presence of digital abnormalities and hearing loss could reflect the extremely reduced transcript amount in this patient. The patient of Turkish origin (P5) is the only one of all the patients described here for whom an autoimmune hemolytic anaemia was detected at the age of 1 and treated with transfusion. In addition, the patient had severe immunodeficiency and his fibroblasts showed extreme radiosensitivity, similar to other patients with NHEJ1 deficiency. P5 died recently due to a septic shock after bone marrow transplantation at the age of 18 months. Similarly, two of the patients described by Buck et al., (Buck et al. 2006a), one of French origin and one of Turkish origin (this patient carried the same mutation as P5) also died due to a septic shock.

Our study confirms that patients with an NBS-like phenotype can have mutations in the NHEJ1 gene, including multi-exon deletions and that analysis of this gene must be considered for 
patients for whom molecular diagnosis of NBS and LIGIV deficiency has been excluded. One of the families described here is of particular interest because of the high degree of phenotypic variability observed in the affected children which might be associated with the identified XRCC4 gene polymorphisms.

\title{
Web Resourses
}

Accession numbers and URL's for the data presented herein are as follows: NCBI, http://www.ncbi.nlm.nih.gov/; Online Mendelian Inheritance in Man (OMIM), http://www.ncbi.nlm.nih.gov/Omim/; Repeat masker program http://www.repeatmasker.org

\section{Acknowledgments}

We are indebted to all patients and their families who participated in this study. We thank Christian Becker for expert technical assistance. Our special thanks go to the anonymous Referee 2 for the excellent suggestion that modifying factors might affect the phenotypic variability in one of the families.

\section{$\underline{\text { References }}$}

\author{
Ahnesorg P, Smith P, Jackson SP (2006) XLF interacts with the XRCC4-DNA ligase IV \\ complex to promote DNA nonhomologous end-joining. Cell 124: 301-13 \\ Andres SN, Modesti M, Tsai CJ, Chu G, Junop MS (2007) Crystal structure of human XLF: a \\ twist in nonhomologous DNA end-joining. Mol Cell 28: 1093-101
}


Bacolla A, Jaworski A, Larson JE, Jakupciak JP, Chuzhanova N, Abeysinghe SS, O'Connell CD, Cooper DN, Wells RD (2004) Breakpoints of gross deletions coincide with non-B DNA conformations. Proc Natl Acad Sci U S A 101: 14162-7

Barnes DE, Stamp G, Rosewell I, Denzel A, Lindahl T (1998) Targeted disruption of the gene encoding DNA ligase IV leads to lethality in embryonic mice. Curr Biol 8: 1395-8

Ben-Omran TI, Cerosaletti K, Concannon P, Weitzman S, Nezarati MM (2005) A patient with mutations in DNA Ligase IV: clinical features and overlap with Nijmegen breakage syndrome. Am J Med Genet A 137A: 283-7

Berardinelli F, di Masi A, Salvatore M, Banerjee S, Myung K, De Villartay JP, Revy P, Plebani A, Soresina A, Taruscio D, Tanzarella C, Antoccia A (2007) A case report of a patient with microcephaly, facial dysmorphism, chromosomal radiosensitivity and telomere length alterations closely resembling "Nijmegen breakage syndrome" phenotype. Eur J Med Genet 50: 176-87

Bogdanova N, Feshchenko S, Schurmann P, Waltes R, Wieland B, Hillemanns P, Rogov YI, Dammann O, Bremer M, Karstens JH, Sohn C, Varon R, Dork T (2008) Nijmegen Breakage Syndrome mutations and risk of breast cancer. Int J Cancer 122: 802-6

Buck D, Malivert L, de Chasseval R, Barraud A, Fondaneche MC, Sanal O, Plebani A, Stephan JL, Hufnagel M, le Deist F, Fischer A, Durandy A, de Villartay JP, Revy P (2006a) Cernunnos, a novel nonhomologous end-joining factor, is mutated in human immunodeficiency with microcephaly. Cell 124: 287-99

Buck D, Moshous D, de Chasseval R, Ma Y, le Deist F, Cavazzana-Calvo M, Fischer A, Casanova JL, Lieber MR, de Villartay JP (2006b) Severe combined immunodeficiency 
and microcephaly in siblings with hypomorphic mutations in DNA ligase IV. Eur J Immunol 36: 224-35

Cahill D, Connor B, Carney JP (2006) Mechanisms of eukaryotic DNA double strand break repair. Front Biosci 11: 1958-76

Cantagrel V, Lossi AM, Lisgo S, Missirian C, Borges A, Philip N, Fernandez C, Cardoso C, Figarella-Branger D, Moncla A, Lindsay S, Dobyns WB, Villard L (2007) Truncation of NHEJ1 in a patient with polymicrogyria. Hum Mutat 28: 356-64

Carney JP, Maser RS, Olivares H, Davis EM, Le Beau M, Yates JR, 3rd, Hays L, Morgan WF, Petrini JH (1998) The hMre11/hRad50 protein complex and Nijmegen breakage syndrome: linkage of double-strand break repair to the cellular DNA damage response. Cell 93: 477-86

Cavalieri S, Funaro A, Pappi P, Migone N, Gatti RA, Brusco A (2008) Large genomic mutations within the ATM gene detected by MLPA, including a duplication of $41 \mathrm{~kb}$ from exon 4 to 20. Ann Hum Genet 72: 10-8

Cavalieri S, Funaro A, Porcedda P, Turinetto V, Migone N, Gatti RA, Brusco A (2006) ATM mutations in Italian families with ataxia telangiectasia include two distinct large genomic deletions. Hum Mutat 27: 1061

Chang CH, Chang CL, Tsai CW, Wu HC, Chiu CF, Wang RF, Liu CS, Lin CC, Bau DT (2009) Significant association of an XRCC4 single nucleotide polymorphism with bladder cancer susceptibility in Taiwan. Anticancer Res 29: 1777-82

Chen JM, Chuzhanova N, Stenson PD, Ferec C, Cooper DN (2005) Complex gene rearrangements caused by serial replication slippage. Hum Mutat 26: 125-34 
Chrzanowska KH, Stumm M, Bekiesiska-Figatowska M, Varon R, Biaecka M, Gregorek H, Michakiewicz J, Krajewska-Walasek M, Jowiak S, Reis A (2001) Atypical clinical picture of the Nijmegen breakage syndrome associated with developmental abnormalities of the brain. J Med Genet 38: E3

Dai Y, Kysela B, Hanakahi LA, Manolis K, Riballo E, Stumm M, Harville TO, West SC, Oettinger MA, Jeggo PA (2003) Nonhomologous end joining and V(D)J recombination require an additional factor. Proc Natl Acad Sci U S A 100: 2462-7

Efstratiadis A, Posakony JW, Maniatis T, Lawn RM, O'Connell C, Spritz RA, DeRiel JK, Forget BG, Weissman SM, Slightom JL, Blechl AE, Smithies O, Baralle FE, Shoulders CC, Proudfoot NJ (1980) The structure and evolution of the human beta-globin gene family. Cell 21: 653-68

Enders A, Fisch P, Schwarz K, Duffner U, Pannicke U, Nikolopoulos E, Peters A, OrlowskaVolk M, Schindler D, Friedrich W, Selle B, Niemeyer C, Ehl S (2006) A severe form of human combined immunodeficiency due to mutations in DNA ligase IV. J Immunol 176: $5060-8$

Engert S, Wappenschmidt B, Betz B, Kast K, Kutsche M, Hellebrand H, Goecke TO, Kiechle M, Niederacher D, Schmutzler RK, Meindl A (2008) MLPA screening in the BRCA1 gene from 1,506 German hereditary breast cancer cases: novel deletions, frequent involvement of exon 17, and occurrence in single early-onset cases. Hum Mutat 29: 948-58

Fernet M, Gribaa M, Salih MA, Seidahmed MZ, Hall J, Koenig M (2005) Identification and functional consequences of a novel MRE11 mutation affecting 10 Saudi Arabian patients with the ataxia telangiectasia-like disorder. Hum Mol Genet 14: 307-18 
Frank KM, Sekiguchi JM, Seidl KJ, Swat W, Rathbun GA, Cheng HL, Davidson L, Kangaloo L, Alt FW (1998) Late embryonic lethality and impaired V(D)J recombination in mice lacking DNA ligase IV. Nature 396: 173-7

Genin E, Feingold J, Clerget-Darpoux F (2008) Identifying modifier genes of monogenic disease: strategies and difficulties. Hum Genet

Girard PM, Kysela B, Harer CJ, Doherty AJ, Jeggo PA (2004) Analysis of DNA ligase IV mutations found in LIG4 syndrome patients: the impact of two linked polymorphisms. Hum Mol Genet 13: 2369-76

Guenther UP, Schuelke M, Bertini E, D'Amico A, Goemans N, Grohmann K, Hubner C, Varon R (2004) Genomic rearrangements at the IGHMBP2 gene locus in two patients with SMARD1. Hum Genet 115: 319-26

Hentges P, Ahnesorg P, Pitcher RS, Bruce CK, Kysela B, Green AJ, Bianchi J, Wilson TE, Jackson SP, Doherty AJ (2006) Evolutionary and functional conservation of the DNA non-homologous end-joining protein, XLF/Cernunnos. J Biol Chem 281: 37517-26

Hiel JA, Weemaes CM, van Engelen BG, Smeets D, Ligtenberg M, van Der Burgt I, van Den Heuvel LP, Cerosaletti KM, Gabreels FJ, Concannon P (2001) Nijmegen breakage syndrome in a Dutch patient not resulting from a defect in NBS1. J Med Genet 38: E19 Hsu NY, Wang HC, Wang CH, Chang CL, Chiu CF, Lee HZ, Tsai CW, Bau DT (2009) Lung cancer susceptibility and genetic polymorphism of DNA repair gene XRCC4 in Taiwan. Cancer Biomark 5: 159-65

Liu Y, Zhou K, Zhang H, Shugart YY, Chen L, Xu Z, Zhong Y, Liu H, Jin L, Wei Q, Huang F, Lu D, Zhou L (2008) Polymorphisms of LIG4 and XRCC4 involved in the NHEJ pathway interact to modify risk of glioma. Hum Mutat 29: 381-9 
Lu H, Pannicke U, Schwarz K, Lieber MR (2007) Length-dependent binding of human XLF to DNA and stimulation of XRCC4.DNA ligase IV activity. J Biol Chem 282: 11155-62

Magnani C, Cremonesi L, Giunta A, Magnaghi P, Taramelli R, Ferrari M (1996) Short direct repeats at the breakpoints of a novel large deletion in the CFTR gene suggest a likely slipped mispairing mechanism. Hum Genet 98: 102-8

Maraschio P, Spadoni E, Tanzarella C, Antoccia A, Di Masi A, Maghnie M, Varon R, Demuth I, Tiepolo L, Danesino C (2003) Genetic heterogeneity for a Nijmegen breakage-like syndrome. Clin Genet 63: 283-90

Masson E, Le Marechal C, Chen JM, Frebourg T, Lerebours E, Ferec C (2006) Detection of a large genomic deletion in the pancreatic secretory trypsin inhibitor (SPINK1) gene. Eur J Hum Genet 14: 1204-8

Nalla VK, Rogan PK (2005) Automated splicing mutation analysis by information theory. Hum Mutat 25: 334-42

Neveling K, Bechtold A, Hoehn H (2007) Genetic instability syndromes with progeroid features. Z Gerontol Geriatr 40: 339-48

Niel F, Legendre M, Bienvenu T, Bieth E, Lalau G, Sermet I, Bondeux D, Boukari R, Derelle J, Levy P, Ruszniewski P, Martin J, Costa C, Goossens M, Girodon E (2006) A new large CFTR rearrangement illustrates the importance of searching for complex alleles. Hum Mutat 27: 716-7

Nijmegen breakage syndrome (2000) The International Nijmegen Breakage Syndrome Study Group. Arch Dis Child 82: 400-6

O'Driscoll M, Cerosaletti KM, Girard PM, Dai Y, Stumm M, Kysela B, Hirsch B, Gennery A, Palmer SE, Seidel J, Gatti RA, Varon R, Oettinger MA, Neitzel H, Jeggo PA, Concannon 
P (2001) DNA ligase IV mutations identified in patients exhibiting developmental delay and immunodeficiency. Mol Cell 8: 1175-85

O'Driscoll M, Jeggo PA (2008) The role of the DNA damage response pathways in brain development and microcephaly: insight from human disorders. DNA Repair (Amst) 7: $1039-50$

Revy P, Malivert L, de Villartay JP (2006) Cernunnos-XLF, a recently identified nonhomologous end-joining factor required for the development of the immune system. Curr Opin Allergy Clin Immunol 6: 416-20

Saran A, Abeysinghe DC, Boyd JT (2006) Microelectromechanical system pressure sensor integrated onto optical fiber by anodic bonding. Appl Opt 45: 1737-42

Savino M, Borriello A, D'Apolito M, Criscuolo M, Del Vecchio M, Bianco AM, Di Perna M, Calzone R, Nobili B, Zatterale A, Zelante L, Joenje H, Della Ragione F, Savoia A (2003) Spectrum of FANCA mutations in Italian Fanconi anemia patients: identification of six novel alleles and phenotypic characterization of the S858R variant. Hum Mutat 22: 338-9

Savitsky K, Bar-Shira A, Gilad S, Rotman G, Ziv Y, Vanagaite L, Tagle DA, Smith S, Uziel T, Sfez S, Ashkenazi M, Pecker I, Frydman M, Harnik R, Patanjali SR, Simmons A, Clines GA, Sartiel A, Gatti RA, Chessa L, Sanal O, Lavin MF, Jaspers NG, Taylor AM, Arlett CF, Miki T, Weissman SM, Lovett M, Collins FS, Shiloh Y (1995) A single ataxia telangiectasia gene with a product similar to PI-3 kinase. Science 268: 1749-53

Stewart GS, Maser RS, Stankovic T, Bressan DA, Kaplan MI, Jaspers NG, Raams A, Byrd PJ, Petrini JH, Taylor AM (1999) The DNA double-strand break repair gene hMRE11 is mutated in individuals with an ataxia-telangiectasia-like disorder. Cell 99: 577-87 
Takata M, Sasaki MS, Sonoda E, Morrison C, Hashimoto M, Utsumi H, Yamaguchi-Iwai Y, Shinohara A, Takeda S (1998) Homologous recombination and non-homologous endjoining pathways of DNA double-strand break repair have overlapping roles in the maintenance of chromosomal integrity in vertebrate cells. Embo J 17: 5497-508

Taulan M, Girardet A, Guittard C, Altieri JP, Templin C, Beroud C, des Georges M, Claustres M (2007) Large genomic rearrangements in the CFTR gene contribute to CBAVD. BMC Med Genet 8: 22

Tsai CJ, Kim SA, Chu G (2007) Cernunnos/XLF promotes the ligation of mismatched and noncohesive DNA ends. Proc Natl Acad Sci U S A 104: 7851-6

van Gent DC, van der Burg M (2007) Non-homologous end-joining, a sticky affair. Oncogene 26: $7731-40$

Varon R, Dutrannoy V, Weikert G, Tanzarella C, Antoccia A, Stockl L, Spadoni E, Kruger LA, di Masi A, Sperling K, Digweed M, Maraschio P (2006) Mild Nijmegen breakage syndrome phenotype due to alternative splicing. Hum Mol Genet 15: 679-89

Varon R, Vissinga C, Platzer M, Cerosaletti KM, Chrzanowska KH, Saar K, Beckmann G, Seemanova E, Cooper PR, Nowak NJ, Stumm M, Weemaes CM, Gatti RA, Wilson RK, Digweed M, Rosenthal A, Sperling K, Concannon P, Reis A (1998) Nibrin, a novel DNA double-strand break repair protein, is mutated in Nijmegen breakage syndrome. Cell 93: 467-76

Warcoin M, Lespinasse J, Despouy G, Dubois d'Enghien C, Lauge A, Portnoi MF, ChristinMaitre S, Stoppa-Lyonnet D, Stern MH (2009) Fertility defects revealing germline biallelic nonsense NBN mutations. Hum Mutat 30: 424-30 


\author{
Yano K, Morotomi-Yano K, Wang SY, Uematsu N, Lee KJ, Asaithamby A, Weterings E, Chen \\ DJ (2008) Ku recruits XLF to DNA double-strand breaks. EMBO Rep 9: 91-6 \\ Yen CY, Liu SY, Chen CH, Tseng HF, Chuang LY, Yang CH, Lin YC, Wen CH, Chiang WF, \\ Ho CH, Chen HC, Wang ST, Lin CW, Chang HW (2008) Combinational polymorphisms \\ of four DNA repair genes XRCC1, XRCC2, XRCC3, and XRCC4 and their association \\ with oral cancer in Taiwan. J Oral Pathol Med 37: 271-7 \\ Yeoh EE, Holloway RH, Fraser RJ, Botten RJ, Di Matteo AC, Butters J, Weerasinghe S, \\ Abeysinghe P (2006) Hypofractionated versus conventionally fractionated radiation \\ therapy for prostate carcinoma: updated results of a phase III randomized trial. Int J \\ Radiat Oncol Biol Phys 66: 1072-83
}

\title{
Legends to the figures
}

Fig. 1. Molecular analyses in patients 2 and 3. (A) Sequence analysis of NHEJ1. Segments of genomic sequence from exon 4 in a control individual and in P2 showing the heterozygous paternal mutation c.495dupA (p.Asp166ArgfsTer20). (B) RT-PCR evidence of alternative NHEJ1 splicing. RT-PCR was carried out with primers located in exon 1 and exon 4 of the NHEJ1 gene. Two transcripts were identified in P2, P3 and their mother; the expected 576 bp transcript and a second transcript of $186 \mathrm{bp}$, which was not found in control samples (only P2 shown). Lane C - control, Lane P - P2. (C) Sequence analysis of the 186 bp product found in P2, P3 and their mother identified an aberrant in-frame transcript with skipped exons 2 and 3. (D) Haplotype analysis. Haplotypes were constructed for the German family based on 14 polymorphisms (SNPs) found by sequencing of introns 1, 2 and 3 of the NHEJI gene. Each 
phase is represented by a different colour. The haplotype carrying the paternal mutation, c.495dupA (p.Asp166ArgfsTer20), detected in all children, is shown in red and the haplotype carrying the maternal mutation is shown in blue. For all but one SNP, the mother was homozygous and not informative, for the rs55728979 (labelled yellow) in intron 3 of the NHEJ1 gene she was heterozygous. At this site the healthy child was also heterozygous, while the two affected children P2 and P3 were homozygous. This finding suggested that P2 and P3 carry the mutant maternal allele. The three grey coloured SNPs delineate the genomic deletion. (E) Quantitative PCR at the DNA level. Quantitative PCR on DNA with primers covering the NHEJ1 gene from exons 1 to 4 revealed a large maternal genomic deletion of approx. 1,9 $\mathrm{kb}$ from intron 1 to intron 3 of the gene. Patient's DNA is labelled in red, the control DNA is in green. (F) Competitive-PCR. The deletion was confirmed by competitive- PCR with 3 primers. The 494 bp band found in both patients and their mother covers the breakpoints of the deletion and corresponds to the mutant allele. The $663 \mathrm{bp}$ fragment is generated from the wild type allele. $\mathrm{M}$ - mother, P2, P3 and F- father.

(G) Sequence analysis of the deletion breakpoints. Shown is the segment of the sequence analysis of the deletion breakpoint. The preserved splice donor site of intron 1 and splice acceptor site of intron 3 explain the presence of the aberrant transcript found at the RNA level. (H) Immunoblot analysis of NHEJ1 expression. The Western blot shows the expression levels of NHEJ1 protein in lysates of lymphoblastoid cell lines of $\mathrm{P} 3$, the parents and the healthy child compared to a control sample. The same blot was reprobed with an antibody directed towards actin as a loading control. The protein bands are labelled on the right of the blot. P3 shows extremely reduced amount of NHEJ1 protein. 
Fig. 2. Molecular analyses in patient 4. (A) Sequence analysis of NHEJ1. Segments of genomic sequence from exon 4 in a control individual and in P4 showing the heterozygous paternal mutation, c.526C>T(p.R176X). (B) Quantitative PCR at the DNA level. Quantitative PCR on DNA with primers covering the NHEJ1 gene sequence from upstream of exon 1 to exon 4 revealed a large maternal genomic deletion of approx. 6,9 kb. The deletion encompasses $1295 \mathrm{bp}$ upsteam of exon 1, including the region of the minimal promoter of the NHEJ1 gene, 3330bp spanning the sequence between exon 1 and exon 3 and 2329 bp of intron 3. Patient's DNA is labelled in red, the control DNA is in green. (C) Amplification of the deletion breakpoint. The deletion was confirmed by PCR with a forward primer located upstream of exon 1 and a reverse primer in intron 3. The junction fragment of 649 bp could be amplified in DNA from P4 and his mother but not in DNA from the control individual. P4, M - mother, C - control. (D) Sequence analysis of the deletion breakpoints. Shown is the segment of the sequence analysis of the deletion breakpoint. The deletion starts 1295bp upstream of exon 1 of the NHEJ1 gene, 3330bp spanning the sequence between exon 1and exon 3 and 2329 bp of intron 3 .

Fig. 3. SNP-analysis. To quantify the alleles carrying the truncating mutations we performed comparative analysis at the DNA and RNA level by the SnapShot method. We used the samples of the corresponding heterozygous parents in order to eliminate the influence of the second mutant allele in the patients. (A) SnapShot analysis of the paternal mutation in the German family; G-Guanosine, A-Adenosine. (B) SnapShot analysis of the mutation in the Turkish family; C-Cytosine, T-Thymidine. While both alleles are almost equally represented at the DNA 
level, at the cDNA level the expression of the allele carrying the truncating mutation is reduced to $\sim 30 \%$ showing that the mRNA from this allele is likely to be eliminated by NMD.

Fig. 4. Cell cycle analysis. Extraordinary sensitivity of cells with $N H E J 1$ gene defects towards ionizing radiation. (A) Cell cycle distribution in a 72-h PHA-stimulated lymphocyte culture from patient P3 without irradiation. Bivariate BrdU-Hoechst 33258 and PI flow cytometry shows scattering of the cells over four cell cycles, I (G0/G1-G2), II G1'-G2'), III (G1',-G2'’) and IV $\left(\mathrm{G} 1^{\prime, \prime}\right)$. (B) Exposure of these cells to $1.5 \mathrm{~Gy}$ irradiation prior to culture initiation results in a collapse of cell cycle progression mainly due to G2 phase accumulation in cycle I such that only very few lymphocytes reach the G1 phase of cycle II (G1'). Arrows indicate increased debris and elevated cell fractions in a resting state $(\mathrm{G} 0 / \mathrm{G} 1)$ and in $\mathrm{G} 2$, respectively. (C) $\mathrm{G} 2$ phase relative to growth fraction ratios of normal control (small gray circles) and ataxia telangiectasia lymphocyte cultures (small gray diamonds) after exposure to $1.5 \mathrm{~Gy}$. The dashed line separates normal control from elevated ranges. The exaggerated responses of lymphocytes from NHEJ1-deficient patients P1 $(\Delta)$, P2 $(\square)$, and P3 $(\nabla)$ towards 1.5 Gy irradiation are indicated by the large shifts of their G2 phase relative to growth fraction ratios (dotted lines) between 0 and 1.5 Gy irradiation. The G2 ratio of irradiated lymphocytes from a patient with DNA ligase IV deficiency (LIG4, O) falls in the mean range of ataxia telangiectasia cells. (D) Dose-response curves reveal greatly increased radiosensivity of ataxia telangiectasia (A-T, gray circles) and DNA ligase IV-deficient (LIG4, open circles) over normal control lymphocytes (CON, gray diamonds) in 72-h cultures. Denoted are means \pm 1 SD. Radiosensitivity of lymphocytes from NHEJ1-deficient patients P1 $(\Delta)$, P2 $(\square)$, and P3 $(\nabla)$ towards $1.5 \mathrm{~Gy}$ irradiation is even greater than that of A-T and LIG4 lymphocytes (t-test, $\mathrm{p}<0.005)$. 
Fig. 5. Analysis of chromosomal instability after irradiation of fibroblasts from P5.

Radiosensitivity was assessed by the chromosomal breakage test in fibroblasts of P5 in response to 0.5 and 1.0 Gy radiation. The cells derived from P5 showed a high rate of spontaneous breakage (0.38; normal range: 0.00 to 0.06$)$ and extremely high levels of damage after IR which were even higher than those of an NBS patient. The percentage of multi-aberrant cells ( $>8$ breaks per cell) was increased to $28 \%$ at $0.5 \mathrm{~Gy}$ and $80 \%$ at $1.0 \mathrm{~Gy}$.

John Wiley \& Sons, Inc. 
Table 1. Clinical and molecular data of five patients with NHEJ1 gene mutations

\begin{tabular}{|c|c|c|c|c|c|}
\hline & P1 & P2* & P3* & $\mathbf{P 4}$ & P5** \\
\hline Age(years) & $\sim 12$ & 6 & 2 & 8 & 1 \\
\hline Origin & Spanish & German & German & Malaysian & Turkish \\
\hline Consanguinity & yes & no & no & no & yes \\
\hline Microcephaly $^{\mathrm{a}}$ & yes & yes & no & yes & yes \\
\hline Clinical features & Facial dysmorphism & & & $\begin{array}{c}\text { Facial dysmorphism } \\
\text { Clinodactyly } \\
\text { Left hearing loss } \\
\end{array}$ & $\begin{array}{l}\text { Autoimmune } \\
\text { haemolytic } \\
\text { anaemia }\end{array}$ \\
\hline Radiosensitivity $^{\mathrm{c}}$ & yes-extreme & yes-extreme & yes-extreme & n.i. & yes-extreme \\
\hline Immunodeficiency $^{d}$ & yes & yes & mild & yes & $\begin{array}{c}\text { yes -severe } \\
\text { died due to sepsis }\end{array}$ \\
\hline Mutation $^{\mathrm{b}}$-paternal & c.168C>G(p.Arg57Gly) & c.495dupA(p.Asp166ArgfsTer20) & 495dupA(p.Asp166ArgfsTer20) & c.526C $>$ T(p.Arg176Ter $)$ & c.532C >T (p.Arg178Ter) \\
\hline Mutation $^{\mathrm{b}}$-maternal & c.168C>G(p.Arg57Gly) & $1.9 \mathrm{~kb}$ deletion & $1.9 \mathrm{~kb}$ deletion & $6.9 \mathrm{~kb}$ deletion & c.532C $>\mathrm{T}$ (p.Arg178Ter) \\
\hline
\end{tabular}

*P2 and P3 are siblings

**A picture of P5 at the age of 41/2 months is shown in Supp. Figure S1

n.i.: no information available

${ }^{\mathbf{a}}$ Head circumference - P2 [32 cm (-4.0 SD)]; P5 [32 cm (-4.0 SD)]; for P1 and P4 - no data available.

${ }^{\mathbf{b}}$ The nomenclature is following Journal guidelines (www.hgvs.org/mutnomen), NHEJ1 RefSeq accession number MN_024782.2. Nucleotide numbering reflects

cDNA numbering with +1 corresponding to the A of the ATG initiation codon in the reference sequence.

${ }^{\mathrm{c}}$ Detailed data is available in Supporting information.

${ }^{\mathrm{d}}$ Detailed data is available in Supporting information. 


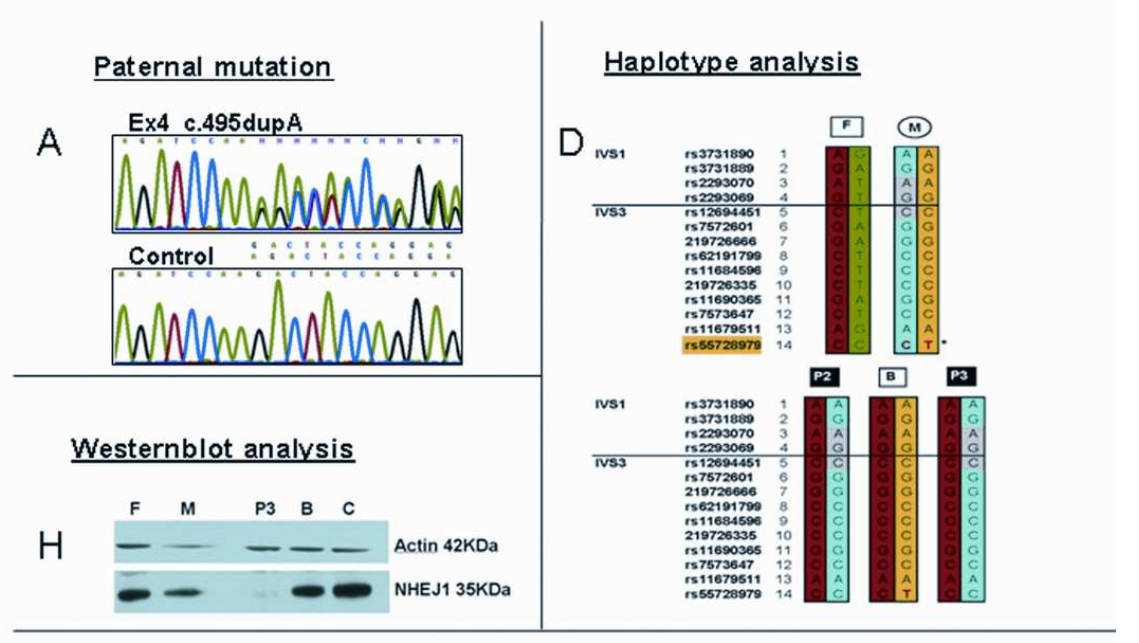

Maternal mutation

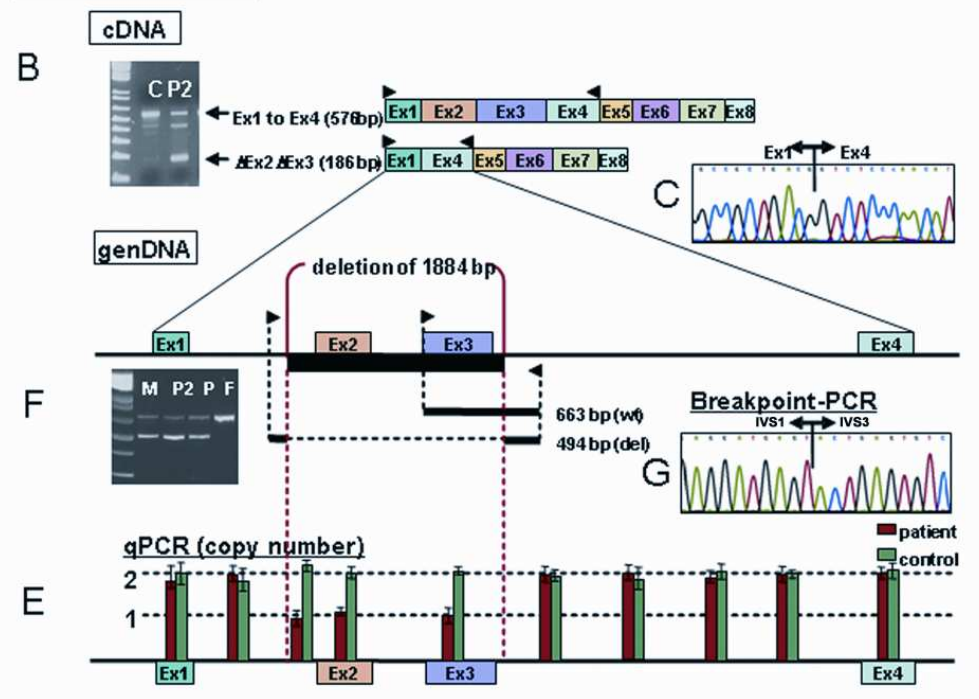

Fig. 1: Molecular analyses in patients 2 and 3. (A) Sequence analysis of NHEJ1. Segments of genomic sequence from exon 4 in a control individual and in P2 showing the heterozygous paternal mutation c.495dupA (p.Asp166ArgfsX20). (B) RT-PCR evidence of alternative NHEJ1 splicing. RTPCR was carried out with primers located in exon 1 and exon 4 of the NHEJ1 gene. Two transcripts were identified in P2, P3 and their mother; the expected 576 bp transcript and a second transcript of $186 \mathrm{bp}$, which was not found in control samples (only P2 shown). Lane C - control, Lane P - P2. (C) Sequence analysis of the 186 bp product found in P2, P3 and their mother identified an aberrant in-frame transcript with skipped exons 2 and 3. (D) Haplotype analysis. Haplotypes were constructed for the German family based on 14 polymorphisms (SNPs) found by sequencing of introns 1,2 and 3 of the NHEJ1 gene. Each phase is represented by a different colour. The haplotype carrying the paternal mutation, c.495dupA (p.Asp166ArgfsX20), detected in all children, is shown in red and the haplotype carrying the maternal mutation is shown in blue. For all but one SNP, the mother was homozygous and not informative, for the rs55728979 (labelled yellow) in 
intron 3 of the NHEJ1 gene she was heterozygous. At this site the healthy child was also heterozygous, while the two affected children P2 and P3 were homozygous. This finding suggested that P2 and P3 carry the mutant maternal allele. The three grey coloured SNPs delineate the genomic deletion. (E) Quantitative PCR at the DNA level. Quantitative PCR on DNA with primers covering the NHEJ1 gene from exons 1 to 4 revealed a large maternal genomic deletion of approx. $1,9 \mathrm{~kb}$ from intron 1 to intron 3 of the gene. Patient's DNA is labelled in red, the control DNA is in green. (F) Competitive-PCR. The deletion was confirmed by competitive- PCR with 3 primers. The $494 \mathrm{bp}$ band found in both patients and their mother covers the breakpoints of the deletion and corresponds to the mutant allele. The $663 \mathrm{bp}$ fragment is generated from the wild type allele. M mother, P2, P3 and F- father.

(G) Sequence analysis of the deletion breakpoints. Shown is the segment of the sequence analysis of the deletion breakpoint. The preserved splice donor site of intron 1 and splice acceptor site of intron 3 explain the presence of the aberrant transcript found at the RNA level. $(\mathrm{H})$ Immunoblot analysis of NHEJ1 expression. The Western blot shows the expression levels of NHEJ1 protein in lysates of lymphoblastoid cell lines of P3, the parents and the healthy child compared to a control sample. The same blot was reprobed with an antibody directed towards actin as a loading control. The protein bands are labelled on the right of the blot. P3 shows extremely reduced amount of NHEJ1 protein.

$140 \times 187 \mathrm{~mm}(200 \times 200$ DPI $)$

John Wiley \& Sons, Inc. 

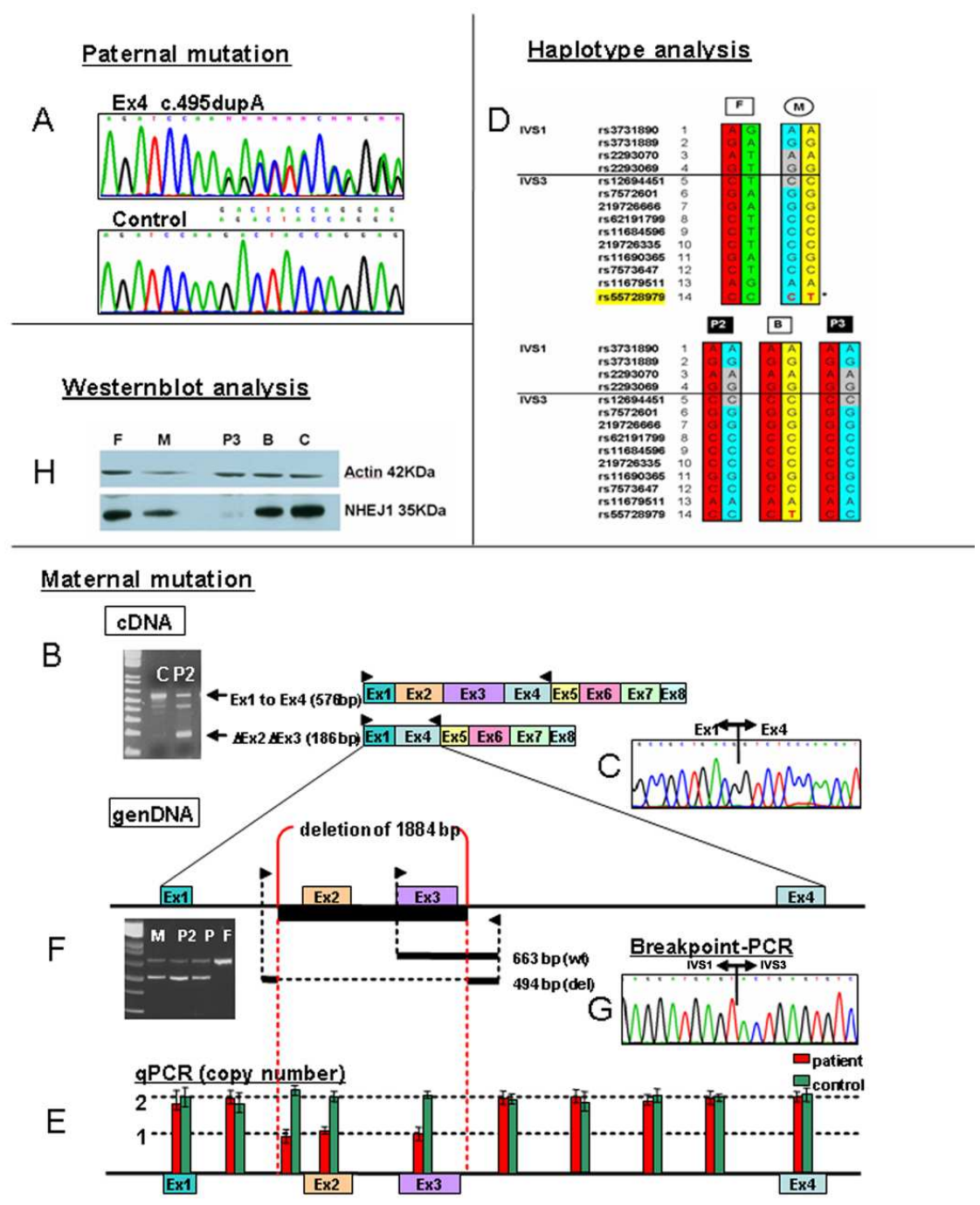

Fig. 1: Molecular analyses in patients 2 and 3. (A) Sequence analysis of NHEJ1. Segments of genomic sequence from exon 4 in a control individual and in $\mathrm{P} 2$ showing the heterozygous paternal mutation c.495dupA (p.Asp166ArgfsX20). (B) RT-PCR evidence of alternative NHEJ1 splicing. RTPCR was carried out with primers located in exon 1 and exon 4 of the NHEJ1 gene. Two transcripts were identified in P2, P3 and their mother; the expected 576 bp transcript and a second transcript of $186 \mathrm{bp}$, which was not found in control samples (only P2 shown). Lane C - control, Lane P - P2. (C) Sequence analysis of the 186 bp product found in P2, P3 and their mother identified an aberrant in-frame transcript with skipped exons 2 and 3. (D) Haplotype analysis. Haplotypes were constructed for the German family based on 14 polymorphisms (SNPs) found by sequencing of introns 1,2 and 3 of the NHEJ1 gene. Each phase is represented by a different colour. The haplotype carrying the paternal mutation, c.495dupA (p.Asp166ArgfsX20), detected in all children, is shown in red and the haplotype carrying the maternal mutation is shown in blue. For all but one 
SNP, the mother was homozygous and not informative, for the rs55728979 (labelled yellow) in intron 3 of the NHEJ1 gene she was heterozygous. At this site the healthy child was also heterozygous, while the two affected children P2 and P3 were homozygous. This finding suggested that P2 and P3 carry the mutant maternal allele. The three grey coloured SNPs delineate the genomic deletion. (E) Quantitative PCR at the DNA level. Quantitative PCR on DNA with primers covering the NHEJ1 gene from exons 1 to 4 revealed a large maternal genomic deletion of approx. $1,9 \mathrm{~kb}$ from intron 1 to intron 3 of the gene. Patient's DNA is labelled in red, the control DNA is in green. (F) Competitive-PCR. The deletion was confirmed by competitive- PCR with 3 primers. The $494 \mathrm{bp}$ band found in both patients and their mother covers the breakpoints of the deletion and corresponds to the mutant allele. The $663 \mathrm{bp}$ fragment is generated from the wild type allele. $\mathrm{M}-$ mother, P2, P3 and F- father.

(G) Sequence analysis of the deletion breakpoints. Shown is the segment of the sequence analysis of the deletion breakpoint. The preserved splice donor site of intron 1 and splice acceptor site of intron 3 explain the presence of the aberrant transcript found at the RNA level. (H) Immunoblot analysis of NHEJ1 expression. The Western blot shows the expression levels of NHEJ1 protein in lysates of lymphoblastoid cell lines of P3, the parents and the healthy child compared to a control sample. The same blot was reprobed with an antibody directed towards actin as a loading control. The protein bands are labelled on the right of the blot. P3 shows extremely reduced amount of NHEJ1 protein.

$140 \times 187 \mathrm{~mm}(200 \times 200$ DPI $)$

20 
Fig. 2: Molecular analyses in patient 4

(A) Sequence analysis of NHEJ1. Segments of genomic sequence from exon 4 in a control individual and in P4 showing the heterozygous paternal mutation, c.526C > T(p.R176X).

(B) Quantitative PCR at the DNA level. Quantitative PCR on DNA with primers covering the NHEJ1 gene sequence from upstream of exon 1 to exon 4 revealed a large maternal genomic deletion of approx. 6,9 kb. The deletion encompasses $1295 \mathrm{bp}$ upsteam of exon 1, including the region of the minimal promoter of the NHEJ1 gene, 3330bp spanning the sequence between exon 1 and exon 3 and 2329 bp of intron 3. Patient's DNA is labelled in red, the control DNA is in green. (C) Amplification of the deletion breakpoint. The deletion was confirmed by PCR with a forward primer located upstream of exon 1 and a reverse primer in intron 3. The junction fragment of 649 bp could be amplified in DNA from P4 and his mother but not in DNA from the control individual. P4, M mother, C - control. (D) Sequence analysis of the deletion breakpoints. Shown is the segment of the sequence analysis of the deletion breakpoint. The deletion starts $1295 \mathrm{bp}$ upstream of exon 1 of the NHEJ1 gene, 3330bp spanning the sequence between exon 1and exon 3 and 2329 bp of intron 3. $149 \times 112 \mathrm{~mm}(200 \times 200$ DPI $)$ 
Fig. 2: Molecular analyses in patient 4

(A) Sequence analysis of NHEJ1. Segments of genomic sequence from exon 4 in a control individual and in P4 showing the heterozygous paternal mutation, c.526C>T(p.R176X).

(B) Quantitative PCR at the DNA level. Quantitative PCR on DNA with primers covering the NHEJ1 gene sequence from upstream of exon 1 to exon 4 revealed a large maternal genomic deletion of approx. 6,9 kb. The deletion encompasses $1295 \mathrm{bp}$ upsteam of exon 1, including the region of the minimal promoter of the NHEJ1 gene, 3330bp spanning the sequence between exon 1 and exon 3 and 2329 bp of intron 3. Patient's DNA is labelled in red, the control DNA is in green. (C) Amplification of the deletion breakpoint. The deletion was confirmed by PCR with a forward primer located upstream of exon 1 and a reverse primer in intron 3. The junction fragment of 649 bp could be amplified in DNA from P4 and his mother but not in DNA from the control individual. P4, M mother, C - control. (D) Sequence analysis of the deletion breakpoints. Shown is the segment of the sequence analysis of the deletion breakpoint. The deletion starts $1295 \mathrm{bp}$ upstream of exon 1 of the NHEJ1 gene, 3330bp spanning the sequence between exon 1and exon 3 and 2329 bp of intron 3. $149 \times 112 \mathrm{~mm}(200 \times 200 \mathrm{DPI})$ 

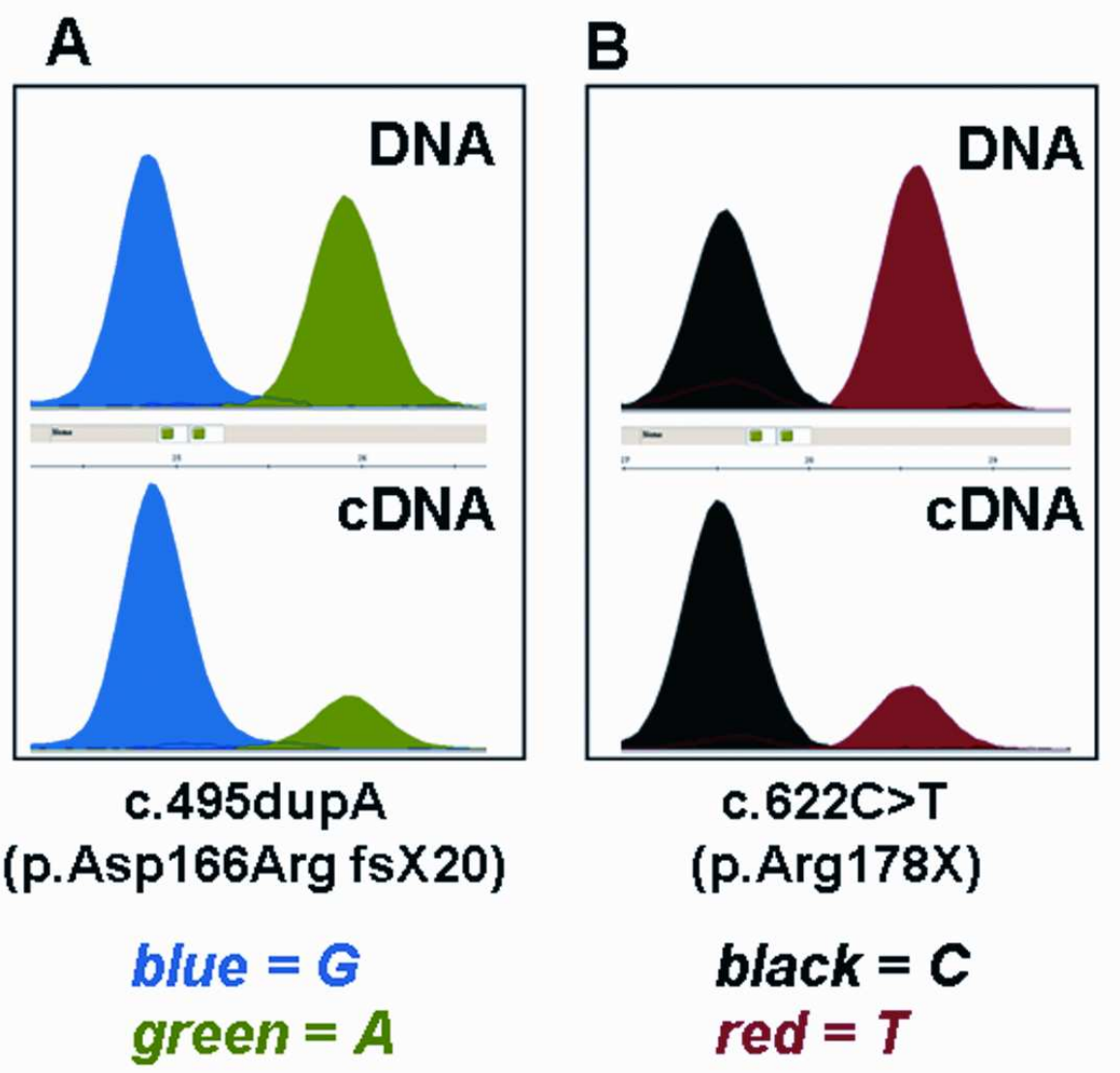

Fig. 3: SNP-analysis

To quantify the alleles carrying the truncating mutations we performed comparative analysis at the DNA and RNA level by the SnapShot method. We used the samples of the corresponding heterozygous parents in order to eliminate the influence of the second mutant allele in the patients. (A) SnapShot analysis of the paternal mutation in the German family; G-Guanosine, A-Adenosine. (B) SnapShot analysis of the mutation in the Turkish family; C-Cytosine, T-Thymidine. While both alleles are almost equally represented at the DNA level, at the cDNA level the expression of the allele carrying the truncating mutation is reduced to $~ 30 \%$ showing that the mRNA from this allele is likely to be eliminated by NMD.

$153 \times 143 \mathrm{~mm}(200 \times 200$ DPI $)$

John Wiley \& Sons, Inc. 

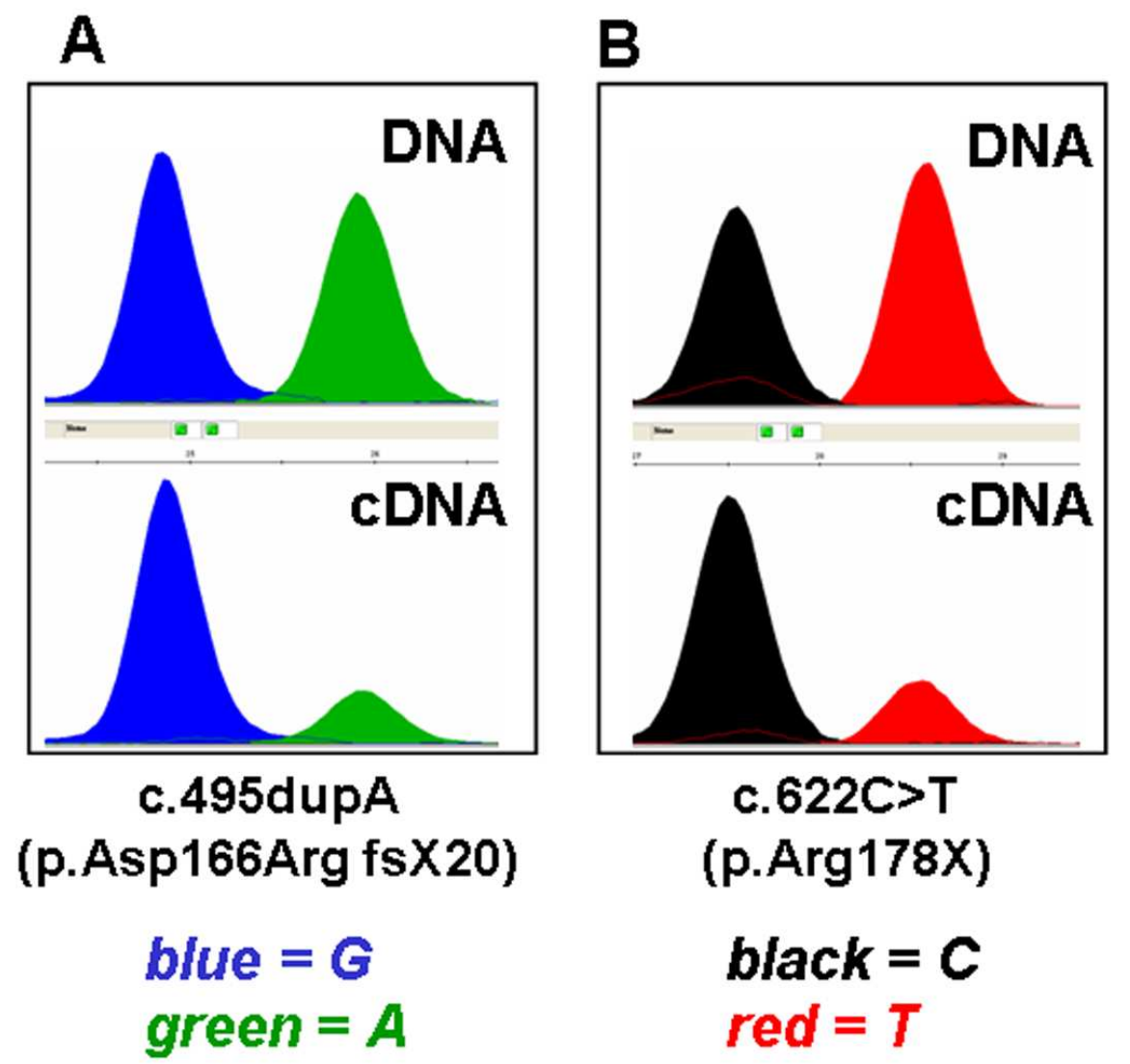

Fig. 3: SNP-analysis

To quantify the alleles carrying the truncating mutations we performed comparative analysis at the DNA and RNA level by the SnapShot method. We used the samples of the corresponding heterozygous parents in order to eliminate the influence of the second mutant allele in the patients. (A) SnapShot analysis of the paternal mutation in the German family; G-Guanosine, A-Adenosine. (B) SnapShot analysis of the mutation in the Turkish family; C-Cytosine, T-Thymidine. While both alleles are almost equally represented at the DNA level, at the cDNA level the expression of the allele carrying the truncating mutation is reduced to $\sim 30 \%$ showing that the mRNA from this allele is likely to be eliminated by NMD.

$153 \times 143 \mathrm{~mm}(200 \times 200 \mathrm{DPI})$ 

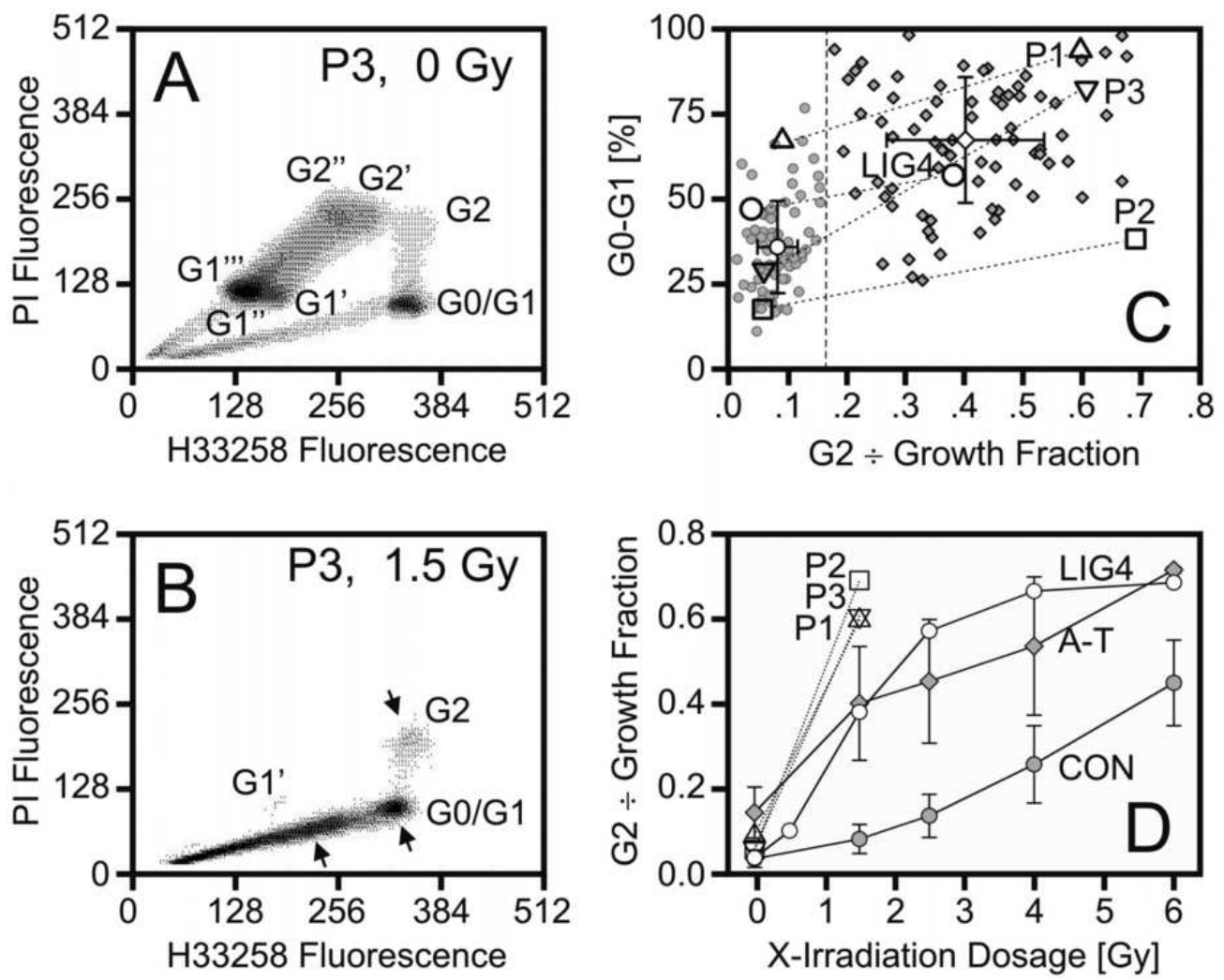

Fig. 4: Cell cycle analysis

Extraordinary sensitivity of cells with NHEJ1 gene defects towards ionizing radiation. (A) Cell cycle distribution in a 72-h PHA-stimulated lymphocyte culture from patient P3 without irradiation. Bivariate BrdU-Hoechst 33258 and PI flow cytometry shows scattering of the cells over four cell cycles, I (G0/G1-G2), II G1'-G2'), III (G1"'-G2") and IV (G1'"). (B) Exposure of these cells to 1.5 Gy irradiation prior to culture initiation results in a collapse of cell cycle progression mainly due to $\mathrm{G} 2$ phase accumulation in cycle I such that only very few lymphocytes reach the G1 phase of cycle II $\left(\mathrm{G} 1^{\prime}\right)$. Arrows indicate increased debris and elevated cell fractions in a resting state (G0/G1) and in G2, respectively. (C) G2 phase relative to growth fraction ratios of normal control (small gray circles) and ataxia telangiectasia lymphocyte cultures (small gray diamonds) after exposure to 1.5 Gy. The dashed line separates normal control from elevated ranges. The exaggerated responses of lymphocytes from NHEJ1-deficient patients P1 $(\Delta)$, P2 $(\square)$, and P3 $(\nabla)$ towards 1.5 Gy irradiation are indicated by the large shifts of their $\mathrm{G} 2$ phase relative to growth fraction ratios (dotted lines) between 0 and 1.5 Gy irradiation. The G2 ratio of irradiated lymphocytes from a patient with DNA ligase IV deficiency (LIG4, O) falls in the mean range of ataxia telangiectasia cells. (D) Doseresponse curves reveal greatly increased radiosensivity of ataxia telangiectasia (A-T, gray circles) and DNA ligase IV-deficient (LIG4, open circles) over normal control lymphocytes (CON, gray diamonds) in 72-h cultures. Denoted are means \pm 1 SD. Radiosensitivity of lymphocytes from NHEJ1-deficient patients $\mathrm{P} 1(\Delta), \mathrm{P} 2(\square)$, and P3 $(\nabla)$ towards $1.5 \mathrm{~Gy}$ irradiation is even greater than that of A-T and LIG4 lymphocytes ( $t$-test, $p<0.005$ ). 
A

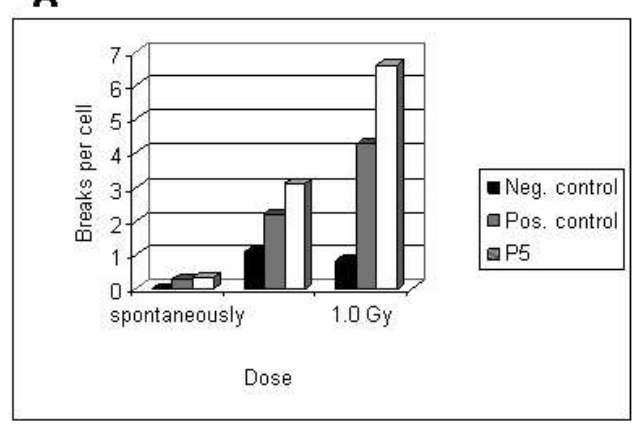

B

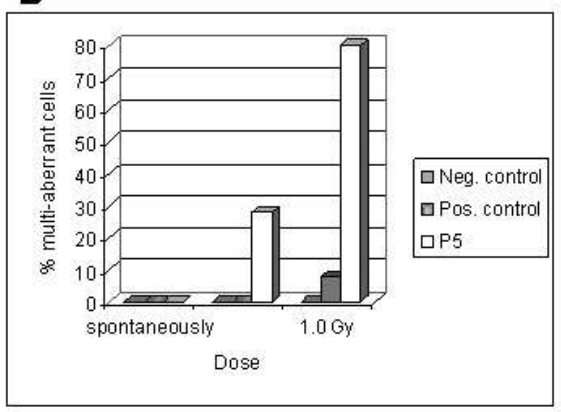

Fig. 5: Analysis of chromosomal instability after irradiation of fibroblasts from P5. Radiosensitivity was assessed by the chromosomal breakage test in fibroblasts of P5 in response to 0.5 and 1.0 Gy radiation. The cells derived from P5 showed a high rate of spontaneous breakage (0.38; normal range: 0.00 to 0.06 ) and extremely high levels of damage after IR which were even higher than those of an NBS patient. The percentage of multi-aberrant cells ( $>8$ breaks per cell) was increased to $28 \%$ at $0.5 \mathrm{~Gy}$ and $80 \%$ at $1.0 \mathrm{~Gy}$.

$102 \times 38 \mathrm{~mm}(200 \times 200 \mathrm{DPI})$ 


\section{Supporting Information}

\section{Patients - Clinical Description}

\section{Patient 1 (P1)}

The patient was born in a consanguineous Spanish family, the parents are $2^{\text {nd }}$ degree cousins. The family also has two healthy children. The affected boy presented with microcephaly, developmental delay, immunodeficiency, and recurrent respiratory infections. The patient's cells showed radiosensitivity.

\section{Patient 2 (P2) and Patient 3 (P3)}

P2 was the first liveborn male child in a German family. The family pedigree contained 5 stillbirths, most probably due to a balanced paternal translocation;

46, XY t (11;22)(q23;q11.2). The pregnancy was uneventful and P2 was delivered at term. The boy had a birth weight of $2480 \mathrm{~g}(-3,6 \mathrm{SD})$, length of $44 \mathrm{~cm}(-4,2 \mathrm{SD})$ and head circumference of $32 \mathrm{~cm}(-4,0 \mathrm{SD})$. The diagnosis NBS was suspected at the age of 4 due to microcephaly, urinary tract infection, diarrhoea, persistent lymphopenia (lymphocyte count 600/ $\mu$ ), neutropenia, hypogammaglobulinemia with B-cell deficiency. DNA of the child was referred to our laboratory at the age of 4 years 9 months for molecular diagnosis of NBS. At the age of $611 / 12$ he presented with a height of $117 \mathrm{~cm}(-1,25 \mathrm{SD})$, weight of $19.6 \mathrm{~kg}(-0,3 \mathrm{SD})$ and head circumference of $47 \mathrm{~cm}$ (-3,8 SD). Regular immunoglobulin replacement therapy keeps the child in relative good health and even allows him to attend a regular school.

A healthy brother was born three years later and at the time the molecular analysis for P2 was carried out, the family was expecting their third child. Since no mutations were detected either in the NBN or LIGIV genes the family continued the pregnancy. The third child was born at $39^{\text {th }}$ week of gestation after an uneventful pregnancy with normal weight $(3170 \mathrm{~g})$ and length $(49 \mathrm{~cm})$ and no microcephaly (head circumference $38 \mathrm{~cm}$ ). Shortly after birth, several episodes of respiratory infections revealed a slight but persistent lymphopenia (lymphocyte count 1200/ $\mu$ ) and low IgA and IgG levels, suggesting that the newborn might suffer from the same disease as his older brother. Follow-up at the age of 1 confirmed the slight combined immunodeficiency and the absence of microcephaly. The child receives no immunoglobulin replacement therapy and is currently in a good health.

\section{Patient 4 (P4)}

An 8-year-old boy of Malaysian origin with the clinical features of NBS was referred to our laboratory for molecular analysis. The child presented with microcephaly, facial dysmorphism, and immunodeficiency due to panhypogammaglobulinemia. In addition, clinodactyly and profound left sided hearing loss were present. At the age of 2 years, thrombocytopenia was detected, which has been cured after 2 years of treatment. Cytogenetic analysis showed increased sensitivity towards mitomycin $\mathrm{C}$ which initially suggested Fanconi anemia. The child's condition remains relatively good due to regular immunoglobulin transfusions and Bactrim prophylaxis.

\section{Patient 5 (P5)}

P5 was born to consanguineous parents of Turkish origin as a first child. The pregnancy was uneventful; the boy was delivered at term with Apgar scores of 9/10/10. His birth weight was $2290 \mathrm{~g}$ (-4.2 SD), length 49cm (-1,7 SD) and head circumference $32 \mathrm{~cm}$ (-4.0 SD). Supp. Figure 
S1 shows the patient at the age of $41 / 2$ months. At the age of 9 months the child was hospitalized because of dystrophy and mouth lesions. At 10 months the weight was $5200 \mathrm{~g}$ (-3.3 SD), length $64 \mathrm{~cm}(-2.8 \mathrm{SD})$ and head circumference $38.5 \mathrm{~cm}$ (-5.3 SD). Based on microcephaly, failure to thrive and severe immunodeficiency, due to B- and T- cell deficiency and absolute lymphopenia, the diagnosis NBS was suspected. At the age of 12 months severe autoimmune haemolytic anaemia (HB:2,5g\%) was detected and treated by blood transfusions and, later, bone marrow transplantation was carried out. The child died at the age of $\sim 18$ months due to sepsis. 

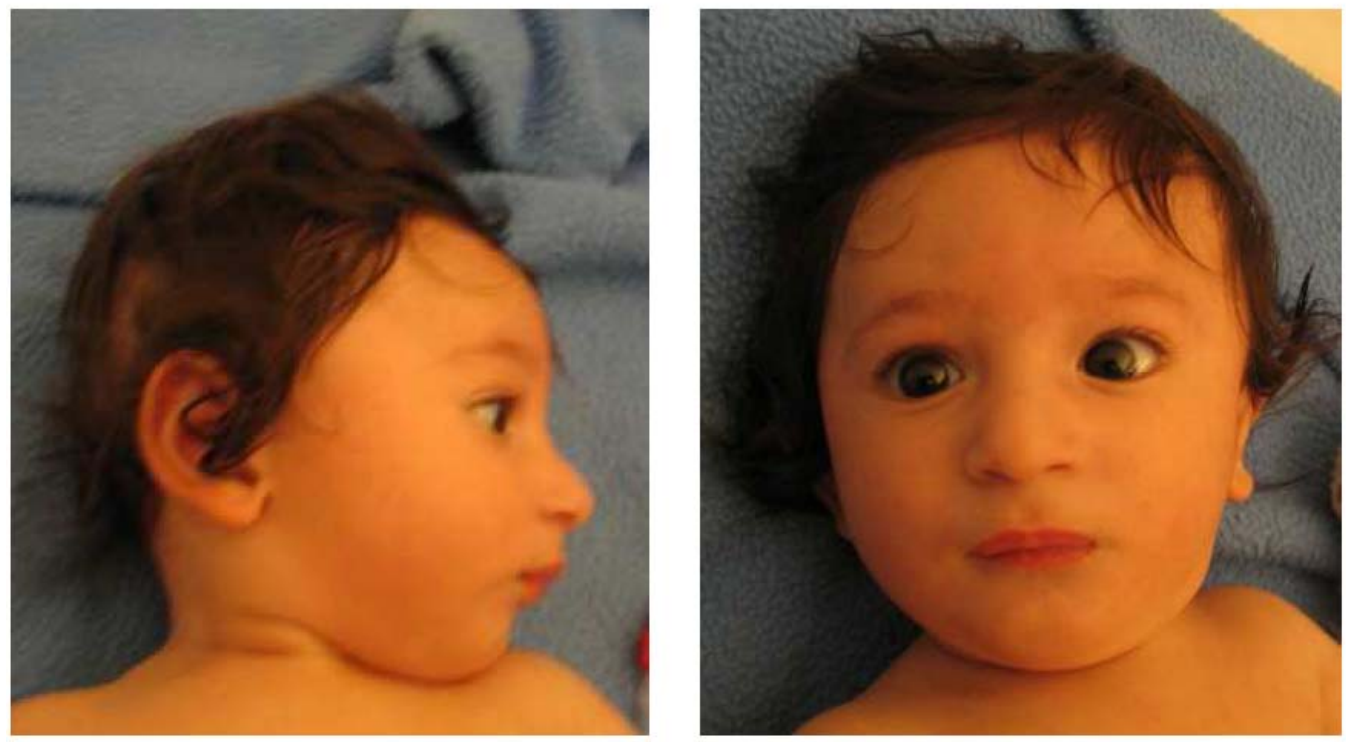

Supp. Figure S1. The picture shows the patient at the age of $41 / 2$ months, note the typical facial NBS-like appearance.

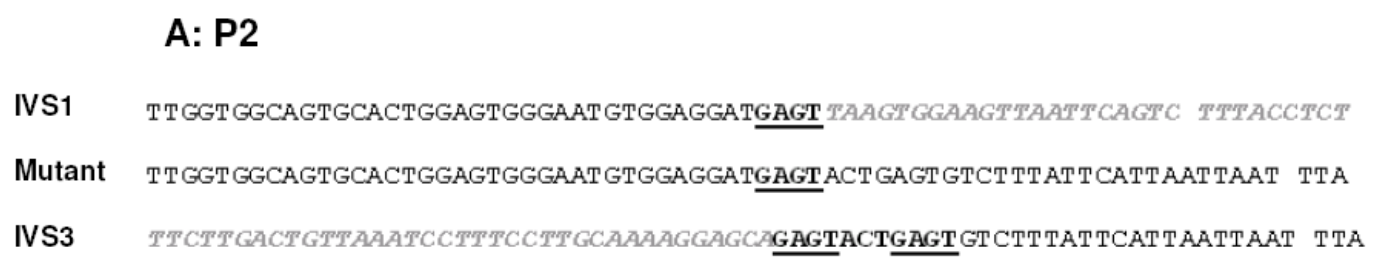

\section{A: P4}

5' End AATGCCTCAGAAGCCCAGGGÄGAAGGCTGCTCAAGTGT ACAGACTTCTTTCCCCATCCAAAAAACCTCTGTCCC

Mutant AATGCCTCAGAAGCCCAGGGAGAAGGCT GCTCAAGTGT ACAGACATGGACCTAGAAAT GCGGAAT ATGTAGT IVS3

Supp. Figure S2. Nucleotide sequences of the deletion junction and the corresponding 5' and 3' breakpoints in P2 and P4. (A) A short 4bp region of homology, GAGT, at the breakpoints and the deletion junction is underlined. A second GAGT repeat is located 3 bp after the 3' breakpoint. The 3 bp separating the two GAGT repeats - ACT are inverted to the last 3 bp of GAGT. (B) A 2bp short region of homology $\mathrm{AC}$ at the breakpoints and the deletion junction is underlined. 
Supp. Table S1. Primers used for quantitative PCR to detect genomic deletions within the NHEJ1 gene

\begin{tabular}{|l|l|}
\hline Primer & Sequence \\
\hline qPCRXLF_Ex1F & TATCCCAAGACCCTGCCTCC \\
\hline qPCRXLF_Ex1R & ACTCTCTTAGCCGCACGCAC \\
\hline qPCRXLF_Ex2F & TTTTATCACCAAGCAGGGCTATG \\
\hline qPCRXLF_Ex2R & TCGCTGGCTGACCACACTAG \\
\hline qPCRXLF_Ex3F & CTCCTTCGCCCATTGTTGAA \\
\hline qPCRXLF_Ex3R & AATCAGTGCATCTGCCACAC \\
\hline qPCRXLF_Ex6F & GGCATGCAGCATTGGTGAT \\
\hline qPCRXLF_Ex6R & CTTGATGCTTCTGTCCCACTTG \\
\hline qPCRXLF_Ex7F & AGATCCTCATACCTCAAACAGTGCTT \\
\hline qPCRXLF_Ex7R & GGCTGAGGAGACCAGTTGTTCT \\
\hline
\end{tabular}

Exon numbering according to transcript ENST00000356853, Ensembl vs57 